\title{
Environmental change impacts on the C- and N-cycle of European forests: a model comparison study
}

\author{
D. R. Cameron ${ }^{1}$, M. Van Oijen ${ }^{1}$, C. Werner ${ }^{2,6}$, K. Butterbach-Bahl ${ }^{2}$, R. Grote ${ }^{2}$, E. Haas ${ }^{2}$, G. B. M. Heuvelink ${ }^{3}$, \\ R. Kiese ${ }^{2}$, J. Kros ${ }^{3}$, M. Kuhnert ${ }^{4}$, A. Leip ${ }^{5}$, G. J. Reinds ${ }^{3}$, H. I. Reuter ${ }^{7}$, M. J. Schelhaas ${ }^{3}$, W. De Vries ${ }^{3,8}$, and \\ J. Yeluripati ${ }^{4}$ \\ ${ }^{1}$ Centre for Ecology and Hydrology, CEH-Edinburgh, Bush Estate, Penicuik EH26 0QB, United Kingdom \\ ${ }^{2}$ Karlsruhe Institute of Technology, Institute of Meteorology and Climate Research, Atmospheric Environmental Research \\ (IMK-IFU), Kreuzeckbahnstr. 19, 82467 Garmisch-Partenkirchen, Germany \\ ${ }^{3}$ Alterra, Wageningen University and Research Centre, P.O. Box 47, 6700 AA Wageningen, the Netherlands \\ ${ }^{4}$ School of Biological Sciences, University of Aberdeen, Cruickshank Building, St Machar Drive, Aberdeen AB24 3UU, \\ United Kingdom \\ ${ }^{5}$ European Commission, DG Joint Research Centre, Institute for Environment and Sustainability, Climate Change Unit \\ (TP 050), Via Enrico Fermi, 2749, 21027 Ispra (Va), Italy \\ ${ }^{6}$ Biodiversity and Climate Research Centre (BiK-F), Frankfurt, Germany \\ ${ }^{7}$ gisxperts gbr, Eichenweg 42, 06849 Dessau, Germany \\ ${ }^{8}$ Environmental Systems Analysis Group, Wageningen University, P.O. Box 47, 6700 AA Wageningen, the Netherlands
}

Correspondence to: D. R. Cameron (dcam@ceh.ac.uk)

Received: 29 June 2012 - Published in Biogeosciences Discuss.: 17 August 2012

Revised: 8 February 2013 - Accepted: 20 February 2013 - Published: 14 March 2013

\begin{abstract}
Forests are important components of the greenhouse gas balance of Europe. There is considerable uncertainty about how predicted changes to climate and nitrogen deposition will perturb the carbon and nitrogen cycles of European forests and thereby alter forest growth, carbon sequestration and $\mathrm{N}_{2} \mathrm{O}$ emission. The present study aimed to quantify the carbon and nitrogen balance, including the exchange of greenhouse gases, of European forests over the period 2010-2030, with a particular emphasis on the spatial variability of change. The analysis was carried out for two tree species: European beech and Scots pine. For this purpose, four different dynamic models were used: BASFOR, DailyDayCent, INTEGRATOR and Landscape-DNDC. These models span a range from semi-empirical to complex mechanistic. Comparison of these models allowed assessment of the extent to which model predictions depended on differences in model inputs and structure. We found a $\mathrm{Eu}-$ ropean average carbon sink of $0.160 \pm 0.020 \mathrm{kgC} \mathrm{m}^{-2} \mathrm{yr}^{-1}$ (pine) and $0.138 \pm 0.062 \mathrm{kgC} \mathrm{m}^{-2} \mathrm{yr}^{-1}$ (beech) and $\mathrm{N}_{2} \mathrm{O}$ source of $0.285 \pm 0.125 \mathrm{kgN} \mathrm{ha}^{-1} \mathrm{yr}^{-1}$ (pine) and $0.575 \pm 0.105 \mathrm{kgNha}^{-1} \mathrm{yr}^{-1}$ (beech). The European av-
\end{abstract}

erage greenhouse gas potential of the carbon sink was 18 (pine) and 8 (beech) times that of the $\mathrm{N}_{2} \mathrm{O}$ source. Carbon sequestration was larger in the trees than in the soil. Carbon sequestration and forest growth were largest in central Europe and lowest in northern Sweden and Finland, N. Poland and S. Spain. No single driver was found to dominate change across Europe. Forests were found to be most sensitive to change in environmental drivers where the drivers were limiting growth, where changes were particularly large or where changes acted in concert. The models disagreed as to which environmental changes were most significant for the geographical variation in forest growth and as to which tree species showed the largest rate of carbon sequestration. Pine and beech forests were found to have differing sensitivities to environmental change, in particular the response to changes in nitrogen and precipitation, with beech forest more vulnerable to drought. There was considerable uncertainty about the geographical location of $\mathrm{N}_{2} \mathrm{O}$ emissions. Two of the models BASFOR and LandscapeDNDC had largest emissions in central Europe where nitrogen deposition and soil nitrogen were largest, whereas the two other models 
identified different regions with large $\mathrm{N}_{2} \mathrm{O}$ emission. $\mathrm{N}_{2} \mathrm{O}$ emissions were found to be larger from beech than pine forests and were found to be particularly sensitive to forest growth.

\section{Introduction}

\subsection{Biogeochemistry of European forests}

According to the Millennium Ecosystem Assessment (2005), forests provide four important services: wood production, regulation of the greenhouse gas (GHG) balance, support of water and soil quality and cultural benefits. The recognition of the regulatory role of forests in carbon sequestration and more generally the overall GHG balance has started to shift the focus of forest research from tree growth to the overall biogeochemistry of forest ecosystems, including both biomass and soils (Van Oijen et al., 2004).

Forests are thought to currently absorb about $10 \%$ of European $\mathrm{CO}_{2}$ emissions (0.11 $\mathrm{Pg} \mathrm{C} \mathrm{yr}^{-1}$ ) (Kauppi et al., 1992; Nabuurs et al., 2003). In a recent study of the European (EU25) carbon balance, Luyssaert et al. (2010) investigated the carbon gained by forests in 1980-2005 through net primary production (NPP) using three approaches, ecosystem modelling, forest inventories and upscaling of ecological data. They found that European forests constitute a net carbon sink of $75 \pm 20 \mathrm{~g} \mathrm{C} \mathrm{m}^{-2} \mathrm{yr}^{-1}$. However, the modelling lacked the important influence of management (thinning and harvesting) and only one of the models considered the influence of nitrogen on the carbon sink.

Forests are dynamic systems and their biogeochemistry undergoes continual change. During the second half of the 20th century, forests were observed to grow faster than before in many parts of Europe (Spiecker, 1999), North America (Turner et al., 1995) and Amazonia (Baker et al., 2004). Ciais et al. (2008) investigated forest inventory data from the EU-15 countries for 1950-2000. They found that in that period carbon biomass stocks had multiplied by 1.75 and that the standing biomass increased linearly with growth (NPP) in both conifers and broadleaved trees so that NPP had also increased by 1.67. Indeed Luyssaert et al. (2010) suggested that forests continue to sequester carbon in spite of intensive harvesting of wood since growth has outpaced losses from harvesting and heterotrophic respiration. This increase in growth has been attributed to a large fraction of young productive trees (Nabuurs et al., 2003), changes in management and increase in forest area (Ciais et al., 2008), increased $\mathrm{CO}_{2}$ (Friedlingstein et al., 1995) and temperature (Myneni et al., 1997).

The role of $\mathrm{N}$ in the carbon cycle whilst sometimes overlooked is also thought to be crucial since it has been found to be a limiting factor for growth in many terrestrial ecosystems (LeBauer and Treseder, 2008; Vitousek and Howarth, 1991). Increased available $\mathrm{N}$ increases leaf $\mathrm{N}$ and photo- synthesis with allocation changes so that more investment is made aboveground at the expense of the roots (Magill et al., 2004; Poorter and Nagel, 2000). However, if other important nutrients, water and climatic drivers are limiting then the importance of $\mathrm{N}$ becomes less significant (Poorter and Nagel, 2000; Wamelink et al., 2009; Luyssaert et al., 2010). Whilst the prominent role of increased $\mathrm{N}$ deposition for the increased growth is undisputed (Kahle et al., 2008; De Vries and Posch, 2011; Magnani et al., 2007; Solberg et al., 2009) there is controversy about the strength of the relationship between the C sink and N. Magnani et al. (2007) conducted an analysis of $\mathrm{CO}_{2}$ fluxes using forest chronosequences. They found that the influence of temperature on photosynthesis and respiration cancelled so that the overwhelming driver of $\mathrm{C}$ sequestration was $\mathrm{N}$ deposition $\left(400-700 \mathrm{~kg} \mathrm{C} \mathrm{kg} \mathrm{N}^{-1}\right)$. However, Dieleman et al. (2010) found that soil nitrogen also influenced microbial activity and, thus, $\mathrm{C}$ decomposition and heterotrophic respiration, reducing the influence of increased $\mathrm{N}$ on soil C. Luyssaert et al. (2010) found that not accounting for $\mathrm{N}$ deposition in BIOME-BGC led to a more modest $11 \pm 30 \%$ lower NPP for EU-25. They also found large regional variation with negligible reductions in growth in northern Europe and the Iberian Peninsula, but in central Europe it could be as much as $20 \%$. Sutton et al. (2008) and others disputed the Magnani et al. (2007) quantification of the relationship between $\mathrm{N}$ deposition and the $\mathrm{C}$ sink. They suggested that if dry deposition and correlations between $\mathrm{N}$ deposition and other environmental drivers such as temperature were included the influence of $\mathrm{N}$ deposition on $\mathrm{C}$ sequestration reduced dramatically from those predicted by Magnani et al. (2007). In a review of evidence from inventories, observations and models De Vries et al. (2009) supported an aboveground accumulation of $\mathrm{C}$ in forests from $\mathrm{N}$ deposition in the range $15-40 \mathrm{~kg} \mathrm{C} \mathrm{kg} \mathrm{N}^{-1}$.

\subsection{Predicting future change}

Because of the importance of carbon sequestration in forests, and the accumulating evidence for changes in its magnitude, recent work has considered the impact of predicted lower $\mathrm{N}$ deposition (Dentener et al., 2006) and climate change on future European forest $\mathrm{C}$ sequestration. Accurate prediction of biogeochemical cycles in European forests is a complex challenge because of the many interacting environmental factors, large spatial heterogeneity and the fact that there is still uncertainty about how best to represent the processes and their inter-linkage in models. For example, Luyssaert et al. (2010) found over- and underestimated NPP in northern and southern latitudes which they attributed to errors in the modelled LAI and problems with underestimating photosynthesis in very dry regions. Considering first climatic changes, modest increases in temperature would be expected to increase enzymatic activity increasing photosynthesis although as temperature increases still further activity is suppressed. In the soil, large increases in temperature will increase microorganism 
activity increasing respiration but this would be counterbalanced by any temperature induced decreases in growth and litter production. Temperature increases could lengthen the growing season in northern latitudes. Increasing temperature will also increase evaporation and water stress on trees (Rebetez and Dobbertin, 2004) and stomatal closing (Zweifel et al., 2007) especially in Mediterranean regions leading to reductions in photosynthesis (Körner, 2003). Increasing atmospheric $\mathrm{CO}_{2}$ concentration stimulates growth and increases water-use efficiency, but trees may acclimate. Whilst $\mathrm{N}$ is limiting, changes in $\mathrm{N}$ deposition would be expected to influence growth, however, any consequential $\mathrm{N}$ saturation in the soil would diminish its influence (Aber et al., 1998; Brumme and Khanna, 2008). De Vries and Posch (2011) modelled the combined past and future effects of climate and $\mathrm{N}$ deposition on tree sequestration by European forests for 1900-2050. They considered two scenarios: no change and change following the SRES A1 scenario and also included limitation by macronutrients other than $\mathrm{N}$. They took a simple modelling approach calculating a reference growth rate from inventory data and made functional changes to this growth rate to simulate the environmental impact using highly smoothed decadal changes in climate and $\mathrm{N}$ deposition. Changes in forest area were not considered and forest management was not included. Their results suggested that past changes were dominated by changes to $\mathrm{N}$ deposition whereas future changes were dominated by climate change. If management and changes in daily weather are considered then this introduces other factors which are likely to be important. Luyssaert et al. (2010) have suggested that factors such as the age class of trees, limitation in nutrients, less precipitation in the spring/summer, increased storm damage due to more intense storms and more extreme events in general such as more frequent and intense summer droughts are likely to influence future growth. There is, therefore, still considerable uncertainty about the possible changes in NPP in the next decades as driven by changes in environmental variables. There is also considerable uncertainty in other factors that will influence $\mathrm{C}$ sequestration. For example, there is substantial uncertainty about the influence of $\mathrm{N}$ deposition on heterotrophic respiration (e.g. Grace, 2004; Dieleman et al., 2010). Also, future harvesting intensity is unlikely to remain static as wood demand is expected to double due to the need for bioenergy (COM, 2008).

\subsection{Aims and methods of the present study}

It is apparent that there is considerable remaining uncertainty about how carbon sequestration from European forests will change in response to predicted environmental changes. While much uncertainty and controversy remains, previous work has highlighted the crucial interaction of the $\mathrm{N}$ and $\mathrm{C}$ cycles for European forests. This will be a particular emphasis of this study and where possible changes to the full C-and $\mathrm{N}$-cycles and their interaction will be quantified and consid- ered. We shall include the impact of management (harvesting and thinning) on forests. This has largely been missing from previous modelling studies of both present (Luyssaert et al., 2010) and future (De Vries and Posch, 2011) carbon sequestration from European forests. Yet Magnani et al. (2007) have suggested that the time since disturbance (harvesting, thinning, etc.) explains $92 \%$ of the total variability in net ecosystem production (NEP). Thus, management will be explicitly included and quantified in this study. Whilst there is much remaining uncertainty in the average European value of the carbon sink, even less is known about the spatial variability of environmental change impacts on European forests. Elucidating regional differences will be an additional emphasis of this study.

The influence of forests in the GHG balance is not restricted to $\mathrm{C}$ sequestration. For example, changes in the $\mathrm{N}$ cycle due to increased nitrogen deposition do not only stimulate plant productivity, but can also lead to increased losses of nitrogen via leaching (Gundersen et al., 2006; Kiese et al., 2011) or enhanced emissions of $\mathrm{N}_{2} \mathrm{O}$ and $\mathrm{NO}$ trace gases from soils (Pilegaard et al., 2006; Kesik et al., 2005) with $\mathrm{N}_{2} \mathrm{O}$ being a harmful atmospheric gas contributing to climate change. Since $\mathrm{N}_{2} \mathrm{O}$ is approximately 310 times as effective as $\mathrm{CO}_{2}$ as a GHG (Solomon et al., 2007) even small quantities emitted from European forests could have a significant influence. Indeed Pilegaard et al. (2006) have suggested that NO and $\mathrm{N}_{2} \mathrm{O}$ emissions from European forests are higher than from other temperate forests in the world. While it is often assumed that the contribution of forests to the European GHG balance is dominated by the carbon sink we know of no conclusive evidence which has established this. Thus, the relative contribution of the carbon sink and the $\mathrm{N}_{2} \mathrm{O}$ source from European forests will be explicitly quantified in this study.

The key questions we aim to answer here are threefold. First, across Europe, what are the geographical variations in forest productivity, carbon sequestration and greenhouse gas balance and where do we expect environmental change to cause the greatest changes? Secondly, which environmental drivers would be the main causes of those changes? Finally, what underlying mechanisms account for the changes, i.e., which components of the carbon and nitrogen balance of forests will be predominantly perturbed?

To answer these questions, we employed four different dynamic models (BASFOR, DailyDayCent, INTEGRATOR and LandscapeDNDC) of sufficient complexity to represent the carbon and nitrogen fluxes through forest ecosystems. The models differed strongly in structure and parameterisation, thus, accounting to some extent for our current uncertainty about biogeochemical mechanisms and their inclusion into process based models. In a novel approach, we chose not to run our models on a regular latitude-longitude grid, but rather to subdivide Europe based on the values of environmental factors that affect forests. This stratification included administrative areas so that subdivisions represented homogeneous forest policy 
and management strategies, homogeneous soils and slope. We focused on near-future (2011-2030) predictions of one coniferous and one deciduous species grown widely across Europe: Scots pine ( Pinus sylvestris L.) and European beech ( Fagus sylvatica $L$.). We chose to look at one possible climate scenario SRES A1b reflecting the fact that the main climate scenarios do not differ greatly in the near term. To consider sensitivity to environmental change we compared results for two decades 2011-2020 and 2021-2030 considering changes to both average weather and $\mathrm{N}$ deposition.

\section{Methods}

\subsection{Model descriptions}

To aid model comparison a table has been created (Table 1) summarising the main model characteristics and initialisation choices. In addition, descriptions of each model are given below.

\subsubsection{BASFOR}

The BASic FORest simulator, BASFOR, (Van Oijen et al., 2005) is a deterministic forest model. The model simulates carbon and nitrogen cycling in trees, soil organic matter and litter. BASFOR is built from well known process representations. Light absorption is calculated by Beer's law. GPP is calculated as light absorption times a light-use efficiency (LUE). NPP is calculated as a fixed ratio of GPP. LUE is temperature-, $\mathrm{CO}_{2-}$ and soil water content-dependent and may be reduced if insufficient nitrogen is taken up by the plants. Potential nitrogen uptake scales with root system surface area. Actual nitrogen uptake is the minimum of demand, determined by tissue $\mathrm{N}$-concentration, and potential uptake. Allocation of assimilates follows allometric rules, but water stress may limit leaf area index (LAI). Turnover of tree and soil components proceeds at temperature-dependent relative rates. The model structure was described by Van Oijen et al. (2005). Papers describing more recent model developments are Van Oijen and Thomson (2010) and Van Oijen et al. (2011).

To find the most plausible BASFOR parametrisation for use across Europe, we employed Bayesian calibration (BC) (Van Oijen et al., 2005), computing the Markov Chain Monte Carlo with an adaptive Metropolis algorithm. Observational data of height, LAI and biomass in stems, branches and foliage were taken from 20 Pinus sylvestris L. and 20 Fagus sylvatica L. sites in Cannell (1982) with an assumed observational error of $10 \%$. In addition, BASFOR was calibrated against observational data of averaged emissions of $\mathrm{N}_{2} \mathrm{O}$ and NO from Bloemerts and De Vries (2009) for 17 pine and 18 beech sites with an assumed error of the maximum of $10 \%$ or $0.5 \mathrm{kgN} \mathrm{ha}^{-1} \mathrm{yr}^{-1}$. This was combined with the initial carbon and nitrogen values calculated as described in Sect. 2.3 with an error of $10 \%$. For the beech forest pa- rameters influencing the phenology of the model were calibrated against COST Action 725 Pan European Phenology Project (http://www.pep725.eu/index.php) budburst and leaf colour data from 17 European sites. The maximum a posteriori (MAP) parameter set was taken as the parametrisation for BASFOR.

\subsubsection{DailyDayCent}

The biogeochemical model DailyDaycent is a daily time step version of the CENTURY model (Parton and Rasmussen, 1994). DailyDaycent simulates decomposition, nutrient flows, soil water and soil temperature. DailyDaycent simulates the biogeochemical processes of $\mathrm{C}, \mathrm{N}$, phosphorus and sulphur cycling associated with SOM dynamics. Key submodels in DayCent model include soil water content and temperature by layer, plant production and allocation of net primary production (NPP), decomposition of litter and soil organic matter, mineralisation of nutrients, $\mathrm{N}$ gas emissions from nitrification and denitrification, and $\mathrm{CH}_{4}$ oxidation in non-saturated soils. NPP is allocated to plant components (e.g. roots vs. shoots) based on vegetation type, phenology, and water/nutrient stress. Nutrient concentrations of plant components vary within specified limits, depending on vegetation type, and nutrient availability relative to plant demand. $\mathrm{N}$ gas fluxes from nitrification and denitrification are driven by soil $\mathrm{NH}_{4}$ and $\mathrm{NO}_{3}$ concentrations, water content, temperature, texture and labile $\mathrm{C}$ availability (Parton et al., 2001). For the different age classes the tree growth is initialised at different years. The growth for age class $0-10 \mathrm{yr}$ starts at 2000 , for age class $10-20 \mathrm{yr}$ at 1990 and so on. Before this initialisation the areas which were assumed to be forests started growing from 1901. This previous forest was cleared and removed before the new planting. Trees of the age classes older than $110 \mathrm{yr}$ started earlier (according to their age) without any previous forest.

\subsubsection{INTEGRATOR}

INTEGRATOR assesses $\mathrm{N}$ and GHG emissions from major terrestrial ecosystems in response to changes in land use, land management and climate at a high spatial resolution for the EU27 (De Vries et al., 2011b). INTEGRATOR includes sub-models for the prediction of $\mathrm{N}$ emissions and $\mathrm{N}$ leaching and $\mathrm{CO}_{2}$ emissions in agricultural and non-agricultural soils. This study is limited to the calculation of $\mathrm{CO}_{2}$ and $\mathrm{N}_{2} \mathrm{O}$ exchange fluxes from forests using the models EFISCEN and YASSO. The model EFISCEN is described in Sect. 2.4.

YASSO (Liski et al., 2003, 2005) is a dynamic soil carbon model consisting of decomposition and woody litter compartments. Allocation of non-woody litter to decomposition compartments is made according to its chemical composition. Woody litter is allocated to fine or coarse compartments based on size. Each woody litter compartment has a fractionation rate that determines the proportion of its contents to be 
Table 1. Characteristics of the four models used in this study.

\begin{tabular}{|c|c|c|c|c|}
\hline & BASFOR & DailyDayCent & INTEGRATOR/YASSO & LandscapeDNDC \\
\hline Timestep & Daily & Daily & Annual & Daily \\
\hline \# State variables(tree, soil) & $14(6,8)$ & $20(10,10)$ & $13(8,5)$ & $38(10,28)$ \\
\hline \# Parameters & 48 & $>100$ & 11 & $>100$ \\
\hline \# Soil levels & 1 & 12 & 1 & $\begin{array}{l}\text { Different for each NCU: } \\
\text { three soil horizons split into } \\
2 \mathrm{~cm}, 5 \mathrm{~cm} \text { and } 10 \mathrm{~cm} \text { layers } \\
\text { plus two litter layers. }\end{array}$ \\
\hline $\begin{array}{l}\text { Driving } \\
\text { environment } \\
\text { variables }\end{array}$ & $\begin{array}{l}\text { Temperature, radiation, } \\
\text { precipitation, humidity, } \\
\text { wind speed, N-deposition, } \\
\mathrm{CO}_{2} \text {. }\end{array}$ & $\begin{array}{l}\text { Temperature, radiation, } \\
\text { precipitation, humidity, } \\
\text { wind speed, N-deposition, } \\
\mathrm{CO}_{2} \text {. }\end{array}$ & $\begin{array}{l}\text { Temperature, radiation, } \\
\text { precipitation, humidity, } \\
\text { N-deposition, } \mathrm{CO}_{2} .\end{array}$ & $\begin{array}{l}\text { Temperature, radiation, } \\
\text { precipitation, } \\
\text { vapour pressure, } \\
\text { N-deposition, } \mathrm{CO}_{2} \text {. }\end{array}$ \\
\hline Plant growth & $\begin{array}{l}\text { Light use efficiency based, } \\
\text { limited by available } \mathrm{N} \text { and } \\
\text { soil water. }\end{array}$ & $\begin{array}{l}\text { Functional dependence on } \\
\text { genetic potential, } \\
\text { phenology, nutrient availability, } \\
\text { water/temperature } \\
\text { stress, and solar radiation. }\end{array}$ & $\begin{array}{l}\text { Model based on measured } \\
\text { growth curves and age } \\
\text { distribution, modified by } \\
\text { climate (temperature and } \\
\text { precipitation) and } \\
\text { nitrogen effects. }\end{array}$ & $\begin{array}{l}\text { Light use efficiency based, } \\
\text { limited by available } \\
\mathrm{N} \text { and soil water. }\end{array}$ \\
\hline Soil pools & Fast, slow and litter & Fast and slow & $\begin{array}{l}\text { Two woody litter } \\
\text { compartments and five } \\
\text { decomposition compartments } \\
\text { (extractives, celluloses } \\
\text { and lignin-like compounds, } \\
\text { humus } 1 \text { and humus2). }\end{array}$ & $\begin{array}{l}\text { Three litter pools } \\
\text { (recalcitrant, labile, } \\
\text { very labile) and two } \\
\text { humus pools (active, non active). }\end{array}$ \\
\hline Soil processes & $\begin{array}{l}\text { Turnover depends on } \\
\text { temperature. }\end{array}$ & $\begin{array}{l}\text { Decomposition of litter and } \\
\text { soil organic matter and } \\
\text { nutrient mineralisation } \\
\text { are functions of substrate } \\
\text { availability, substrate quality } \\
\text { (lignin } \%, \mathrm{C} / \mathrm{N} \text { ratio), } \\
\text { and water/temperature stress. }\end{array}$ & $\begin{array}{l}\text { First order rate constants } \\
\text { depending on temperature } \\
\text { and precipitation minus } \\
\text { potential evapotranspiration } \\
\text { between May and Sep. }\end{array}$ & $\begin{array}{l}\text { Decomposition depends on } \\
\text { temperature, water, and the } \\
\text { population of microbes } \\
\text { which is } \mathrm{N} \text { dependent. }\end{array}$ \\
\hline $\mathrm{N}$ emissions & $\begin{array}{l}\text { Calibrated fraction } \\
\text { of mineral } \mathrm{N} \text {. }\end{array}$ & $\begin{array}{l}\text { Explicit nitrification and } \\
\text { denitrification processes. }\end{array}$ & $\begin{array}{l}\text { Empirical model or } \\
\text { meta-model based on DNDC. }\end{array}$ & $\begin{array}{l}\text { Explicit nitrification and } \\
\text { denitrification processes. }\end{array}$ \\
\hline $\begin{array}{l}\text { Model initialisation } \\
\text { forest }\end{array}$ & EFISCEN & From planting calibrated to EFISCEN. & EFISCEN & EFISCEN \\
\hline $\begin{array}{l}\text { Model initialisation } \\
\text { soil }\end{array}$ & $\begin{array}{l}\text { NitroEurope provided } \\
\text { soil input }\end{array}$ & Initalised to equlibrium & $\begin{array}{l}\text { NitroEurope provided } \\
\text { soil input }\end{array}$ & $\begin{array}{l}\text { NitroEurope provided } \\
\text { soil input }\end{array}$ \\
\hline Soil spinup & $50 \mathrm{yr}$ & $>110 \mathrm{yr}$ & $10-30 \mathrm{yr}$ & $5 \mathrm{yr}$ \\
\hline $\begin{array}{l}\text { Pedo-transfer } \\
\text { functions used in } \\
\text { calculating the soil } \\
\text { water profile }\end{array}$ & $\begin{array}{l}\text { Derived from } \\
\text { Robertson }(1999, \text { p. } 45) \text {. }\end{array}$ & $\begin{array}{l}\text { Derived from Gupta } \\
\text { and Larson (1979); } \\
\text { Rawls et al. (1982). }\end{array}$ & Not required & $\begin{array}{l}\text { Derived using } \\
\text { van Genuchten (1980) formula. }\end{array}$ \\
\hline Thinning & $\begin{array}{l}\text { Decadal } 20 \% \text { thinning for } \\
\text { trees aged } 20 \mathrm{yr} \text { and over. }\end{array}$ & $\begin{array}{l}\text { Decadal } 20 \% \text { thinning for } \\
\text { trees aged } 20 \mathrm{yr} \text { and over. }\end{array}$ & EFISCEN & $\begin{array}{l}\text { Decadal } 20 \% \text { thinning for } \\
\text { trees aged } 20 \mathrm{yr} \text { and over. }\end{array}$ \\
\hline Harvesting & Pine $80 \mathrm{yr}$, beech $100 \mathrm{yr}$ & None & EFISCEN & Pine $80 \mathrm{yr}$, beech $100 \mathrm{yr}$. \\
\hline
\end{tabular}

released to the decomposition compartments in a time step. Each decomposition compartment has a decomposition rate that determines the proportion of its contents to be removed in a time step.

\subsubsection{LandscapeDNDC}

LandscapeDNDC (Haas et al., 2012) describes microclimate, water cycle, plant physiological processes, soil biogeochemistry and silvicultural properties (such as height, diameter and number of trees). The soil biogeochemical part has been recoded from the agricultural DeNitrificationDeComposition (DNDC) model and its forest adaptation PnET-N-DNDC (Li et al., 1992, 2000). For the present study, LandscapeDNDC used the PnET-N physiology module. In addition, the silvicultural tracking routine is called once a year (Grote et al., 2011). Respiration is differentiated into a fixed component (growth respiration) and a fraction depending on temperature and biomass (maintenance respiration). Total carbon is separated into the tree compartments foliage, fine roots and wood, and is accumulated throughout the year and used for foliage and wood growth in the next year. In PnET-N (Li et al., 2000) the nitrogen concentration is calculated from the difference between optimum and actual nitrogen content and the availability of nitrogen in the soil. Litterfall is described from compartment turnover rates considering retranslocation back into the plant before foliage shedding. Litter mineralisation and linked heterotrophic respiration as well as mineral $\mathrm{N}$ release are calculated as described earlier (Li et al., 2000). Ecosystem $\mathrm{N}$ turnover includes plant $\mathrm{N}$ uptake, mineralisation, microbial immobilisation, nitrification, denitrification or leaching considering aerobic as well as anaerobic pathways (Li et al., 2000). 


\subsection{NitroEurope classification units (NCUs)}

To facilitate model computations across Europe, the EU25 plus Norway Switzerland and the Balkan countries $($ EU25+5) region was subdivided into so-called NitroEurope Classification Units (NCUs). These NCUs are composed of multipart polygons, each of the polygons being a cluster of $1 \mathrm{~km} \times 1 \mathrm{~km}$ pixels. The composition of the NCUs were chosen to share the same administrative unit (Nomenclature of Territorial Units NUTS2 and NUTS3, EC, 2003; Statistical Office of the European Communities, 2003), the same soil mapping units (Soil Geographic Database SGDB classification, European Commission, 2004), and are homogeneous with regard to slope (Catchment Characterisation and Modelling Digital Elevation Model, CCM 250 DEM), distinguishing five slope classes (i.e., $0-2 \%, 2-8 \%, 8-15 \%, 15-$ $25 \%,>25 \%)$. The NCUs are a further development from 'Homogeneous Spatial Units' (Leip et al., 2008, 2011). However, as a main difference, a criterion on homogeneous altitude was added for the NCU. To this purpose, the average height of the multi-polygon obtained with the procedure above was compared with the average height of each individual polygon. Those polygons for which this difference was larger than $200 \mathrm{~m}$ were grouped into a separate spatial unit. All maps were re-sampled to a $1 \mathrm{~km}$ raster map (ETRS89 Lambert Azimuthal Equal Area 52N 10E, Annoni, 2005), geographically consistent with the European Reference Grid and Coordinate Reference System proposed under INSPIRE (Infrastructure for Spatial Information in the European Community, Commission of the European Communities, 2004).

\subsection{Initial soil data}

Model simulations required initialisation of soil conditions across the simulated area. Initial soil data were created from spatial averages of predictions of seven soil properties $(\mathrm{pH}$, organic carbon, clay, sand, bulk density, total nitrogen and horizon thickness) for the $\mathrm{A}, \mathrm{B}$ and $\mathrm{C}$ horizons, for all NCUs within EU25+5. Predictions were obtained using a geostatistical regression cokriging approach (Hengl et al., 2004) in which the value of a soil property at some location is derived from observations nearby and correlated environmental factors such as landuse and soil type. Organic carbon and total nitrogen were log transformed prior to the geostatistical modelling. Observations were derived from the ISRIC WISE/SPADE (http://www.isric.org) and the EFSDB datasets. Spatial averages were obtained by taking the arithmetic mean of all predictions within the NCU.

Soil water profiles were calculated for each model separately as given in Table 1 .

\subsection{EFISCEN and initial forest data}

Initial forest data were derived from EFISCEN. The European Forest Information Scenario model (EFISCEN V3.1) simulates the development of forest resources in terms of increment and growing stock changes at scales from provincial to European level (Schelhaas et al., 2007). Data from National Forest Inventories (NFIs) are used to construct the initial age class distribution and growth function for each combination of province, tree species, site class and owner class that can be distinguished in a country. Each of these combinations is assigned a management regime, defined as the probability that a thinning or final harvest can be carried out as a function of age. For each time step, the national amount of wood to be produced from the forest is defined and allocated over the forest types according to the felling possibilities as defined by actual age class distributions and the management regime. Using factors to convert growing stock volumes to biomass (biomass expansion factors, BEFs) and turnover rates, EFISCEN is able to estimate carbon stocks and litterfall.

Initialisation data were taken from the forest resources part of the European Forest Sector Outlook Studies of the UN-ECE (Schelhaas et al., 2006a,b). Since initial data refer to different years for the different countries, all countries were projected until a common year (2005), using historical harvest levels (FAOSTAT, 2009). Results for 2005 were extracted for pine and beech, at the regional level available in EFISCEN (mostly NUTS2 or national). Data included area, timber volume and biomass per compartment per age class. The procedure used was to create an overlay between the NCU map and the EFISCEN regions. Where an NCU straddled more than one EFISCEN region, the region with the largest share in the NCU was assigned. The EFISCEN data were then assigned to the NCUs using the mapping of NCU to EFISCEN regions so that all NCUs within the same region were assumed to have the same forest data.

\subsection{Rotation length and thinning regime}

Trees which were initially aged above the rotation length were considered to be natural unmanaged forests and, therefore, not harvested. The thinning was skipped whenever the forest stand was not closed. This was defined as an LAI of less than 3, a crown-covered area of less than $95 \%$ or an aboveground biomass of less than $4000 \mathrm{~kg} \mathrm{DM} \mathrm{ha}^{-1}$. These restrictions were relaxed for LandscapeDNDC because LAI and ground coverage is calculated from initialised stand properties including stemwood volume so that for stand density all three criteria are intrinsically connected.

\subsection{Climate and $\mathrm{N}$ deposition scenario}

The IPCC SRES A1b scenario (Nakícenovíc et al., 2001) was used in this study.

\subsubsection{Weather driving data}

The weather driving data for A1b were taken from the climate model REMO. Data from REMO model runs provided 
by MPI Hamburg were converted into netcdf data format, merged into $10 \mathrm{yr}$ slices and remapped to a 0.22 degree resolution longitude latitude grid using Climate Data Operators (CDO V1.4.0.1) available from http://www.mpimet.mpg.de/ cdo. Downscaling was performed using a python algorithm based on the libraries numpy, scipy and gdal, sorted according to the respective NCU-order, and converted into a binary file to be used as input model data.

\subsubsection{Nitrogen deposition}

The annual atmospheric $\mathrm{N}$ deposition was calculated on the basis of $\mathrm{NH}_{3}$ and NOx emissions from agro-ecosystems calculated by the INTEGRATOR model (De Vries et al., 2011b), combined with historic EMEP data on NOx emissions and an emission-deposition matrix for $\mathrm{NH}_{3}$ and $\mathrm{NOx}$, derived from the EMEP model (Simpson et al., 2003; Tarrasón et al., 2007). For 2020 the non-agricultural N emission scenario was used that was developed for the Thematic Strategy on Air Pollution of the EU and reflects the current legislation (Amann et al., 2007). From 2020 onwards, the anthropogenic $\mathrm{N}$ emissions were assumed constant.

\subsection{3 $\mathrm{CO}_{2}$ timeseries}

Future $\mathrm{CO}_{2}$ air concentrations consistent with the IPCC SRES A1b scenario (Nakícenovíc et al., 2001) were obtained from Carter (2007).

\section{European Average Results}

\subsection{Greenhouse gas balance}

The models agree on a number of aspects of GHG balance. Firstly that the $\mathrm{CO}_{2}$ sink is larger than the $\mathrm{N}_{2} \mathrm{O}$ emission source (Fig. 1) although, the $\mathrm{CO}_{2}$ sink for DailyDayCent pine is substantially larger than the others. Comparing the GHG balance for the two decades, there is generally a greater $\mathrm{CO}_{2}$ sink in the first decade than in the second, although DailyDayCent pine has the opposite. All the models have larger $\mathrm{N}_{2} \mathrm{O}$ emissions for beech than for pine forests.

There is, however, disagreement on whether pine or beech forests have a greater $\mathrm{CO}_{2}$ sink, with LandscapeDNDC and DailyDayCent having a larger sink for pine forests than beech and BASFOR and INTEGRATOR vise versa. In addition, there are larger changes in $\mathrm{CO}_{2}$ sink strength between decades for BASFOR and INTEGRATOR than for LandscapeDNDC and DailyDayCent.

Three of the models have larger $\mathrm{N}_{2} \mathrm{O}$ emissions in the first decade than in the second whereas BASFOR is the opposite.

\subsection{Forest carbon and nitrogen balance}

To help understand the differences in GHG balance for species, decades and models it is informative to look at the

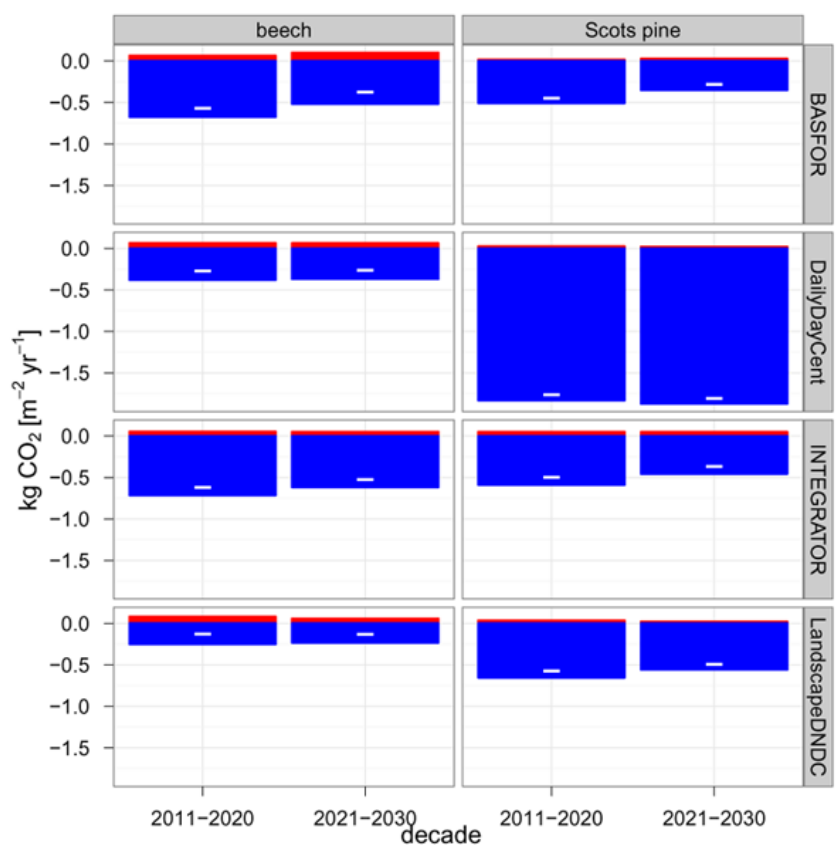

Fig. 1. European average greenhouse gas balance for two dominant forest species (Scots pine and beech) for decades (1) 2011-2020 and (2) 2021-2030. Positive is a source and negative a sink. $\mathrm{N}_{2} \mathrm{O}$ has been scaled with a greenhouse gas warming potential (GWP) of 310 and is in red. $\mathrm{CO}_{2}$ is in blue.

full carbon and nitrogen budgets for both species (pine and beech) and for both decades (Fig. 2). Calculation of the full budget was only possible for two of the models BASFOR and LandscapeDNDC. In this context, a lack of equilibrium or balance reflects a difference between incoming and outgoing fluxes of $\mathrm{C}$ and $\mathrm{N}$ from the trees or the soil and, therefore, implies a change in the stock of $\mathrm{C}$ and $\mathrm{N}$ in the same.

There are a number of similarities in the carbon and nitrogen budgets of the species, decades and models. There is agreement on the dominant fluxes, with NPP and litter being the main $\mathrm{C}$ fluxes and uptake and litter being the largest $\mathrm{N}$ fluxes in trees. The litter flux is more dominant in the $\mathrm{N}$ than the C-cycle, where exported carbon is also significant. In the soil, the principal carbon fluxes are litter and respiration, with litter and uptake dominating the flux of $\mathrm{N}$ into and out from the soil similar to the trees.

\subsubsection{Species differences}

Carbon and nitrogen cycling is more vigorous in beech forests than pine, with a larger $\mathrm{C}$ and $\mathrm{N}$ litter flux to the soil and a larger soil respiration. The larger litter flux is caused by the seasonal loss of foliage and regrowth in deciduous trees. In addition, exported carbon is greater for beech than pine and has a larger $\mathrm{C} / \mathrm{N}$ ratio.

Soil carbon is fairly close to equilibrium for both species, though less so for beech. Both BASFOR and 

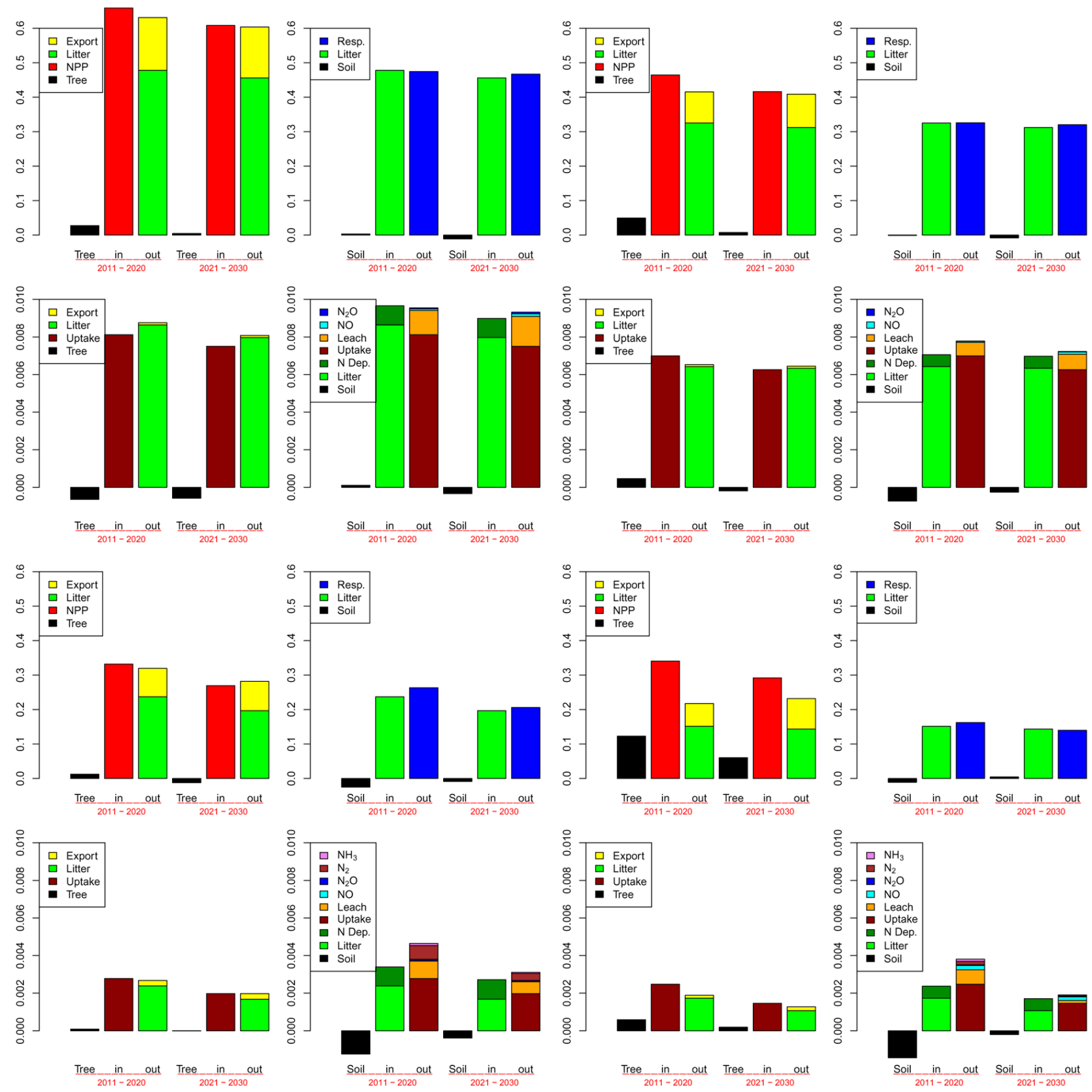

Fig. 2. European average carbon and nitrogen budgets. The plots are grouped in sets of four in which the top and bottom rows are carbon and nitrogen budgets, respectively. The left plots are for trees and the right plots soil. The top set of plots are for BASFOR and the bottom set for LandscapeDNDC. The units are $\mathrm{kgC}$ or $\mathrm{N} \mathrm{m}^{-2} \mathrm{yr}^{-1}$.

LandscapeDNDC have less $\mathrm{NO}$ and more $\mathrm{N}_{2} \mathrm{O}$ emission in beech than in pine. In addition, soil $\mathrm{N}$ leaching is greater in beech than in pine. Lower evapotranspiration fluxes in the dormant vegetation period, the larger flux of nitrogen into the soil by litter and a greater nitrogen deposition in beech than pine forests may help explain the higher leaching and $\mathrm{N}_{2} \mathrm{O}$ fluxes.
Differences between the two decades are less marked for beech than pine with larger imbalances in the second decade.

\subsubsection{Decadal differences}

As noted in Sect. (3.1), sequestration of carbon is reduced in the second decade. In the $\mathrm{C}$ and N budgets it is NPP and nitrogen uptake from the soil that have the largest reductions. While there are reductions in litter flux and soil respiration, 
these are generally less marked. The exception is soil respiration for LandscapeDNDC beech which has a comparable reduction to NPP. Thus, changes in NPP are the major factor in changes in NEE and, hence, the greenhouse gas balance of the forest. Therefore, understanding how NPP has changed is key to understanding how the greenhouse gas balance of forests changed with the environment. The exported carbon is greater in the second decade than in the first. In general, carbon and nitrogen in the soil are in closer balance in the second decade than in the first. An exception is BASFOR beech which is closer to equilibrium in the second decade.

\subsubsection{Model differences}

Carbon and nitrogen cycling is more vigorous in BASFOR than in LandscapeDNDC, with greater NPP, but also a larger litter flux and hence a larger soil respiration.

As noted (Sect. 3.1), the models do not agree on a greater carbon sequestration across species. Indeed, while NPP is clearly greater for pine than beech in BASFOR, it is more closely matched in LandscapeDNDC. In contrast, litter flux and, thus, soil respiration are larger for beech than pine for both models. This explains the lower carbon sequestration for LandscapeDNDC beech in Fig. 1 relative to pine and BASFOR. Further, LandscapeDNDC beech shows a net loss of carbon from the trees whereas pine and BASFOR have net gains. Indeed LandscapeDNDC beech also has a larger decadal reduction in NPP than pine and BASFOR, but this is counteracted by a larger reduction in soil respiration so the change in carbon sequestration between the decades is smaller than for pine and BASFOR (Fig. 1).

Exported carbon is larger for BASFOR than LandscapeD$\mathrm{NDC}$, but exported $\mathrm{N}$ is smaller suggesting a larger $\mathrm{C} / \mathrm{N}$ ratio in the stems for BASFOR. The litter flux is the opposite with BASFOR having a larger relative $\mathrm{N}$ to $\mathrm{C}$ flux than LandscapeDNDC suggesting a lower $\mathrm{C} / \mathrm{N}$ ratio in the roots and leaves.

LandscapeDNDC has larger $\mathrm{N}_{2} \mathrm{O}$ emissions and leaching in the first decade which reduces in the second decade. BASFOR shows increased $\mathrm{N}_{2} \mathrm{O}$ emissions and leaching in the second decade, with larger emissions than LandscapeDNDC. The reduction in leaching is more dramatic for LandscapeDNDC pine than beech.

In general, LandscapeDNDC has larger imbalances in the soil than BASFOR, with a net loss of $\mathrm{N}$ and $\mathrm{C}$ from the soil. As for NPP, the species are reversed with beech in closer balance in BASFOR and pine in closer balance in LandscapeDNDC. For LandscapeDNDC the model is in closer balance in the second decade than in the first for both soil $\mathrm{C}$ and $\mathrm{N}$. Apart from soil $\mathrm{N}$ under pine BASFOR is in closer balance in the first decade. This helps explain the contrasting $\mathrm{N}_{2} \mathrm{O}$ emissions noted above.

\subsection{European averaged climate differences between decades}

In general, the environmental conditions are more favourable for beech forests than pine. Precipitation at beech stands was $14 \%$ and temperature was $0.5^{\circ} \mathrm{C}$ higher. Initial soil nitrogen was $23 \%$ higher and nitrogen deposition was $58 \%$ higher at beech than at pine sites. This may indicate why NPP and NEE were significantly higher for beech than pine in BASFOR and INTEGRATOR although it does not explain the reverse for LandscapeDNDC and DailyDayCent.

Mean climate differences between the two decades were less than those for species, with temperature being $0.03^{\circ} \mathrm{C}$ higher, precipitation $1.2 \%$ lower in pine and temperature $0.06{ }^{\circ} \mathrm{C}$ lower and precipitation $2 \%$ lower in beech. These changes seem small given the $10 \%$ to $20 \%$ changes in NPP/NEE already noted. This is indicative of a response to spatial variation hidden in the mean picture.

\section{Carbon sequestration}

\subsection{Spatial variation in carbon sequestration}

Maps of carbon sequestration and growth averaged over the models present in this study and their standard deviation have been created for pine (Fig. 3) and beech forests (Fig. 4) to highlight model agreement and disagreement and, thus, uncertainty. INTEGRATOR results were not included in the growth maps since unlike the other models, INTEGRATOR does not calculate NPP and plant respiration. INTEGRATOR NEE is the sum of tree carbon sequestration calculated by EFISCEN and soil carbon sequestration calculated by YASSO. While the inclusion of INTEGRATOR results for NEE, but not NPP makes direct comparison of NPP and NEE more opaque, of primary concern for this work was to estimate the structural uncertainty in NPP and NEE by including the maximum number of models possible in our results. In addition, given the large and very probably unrealistic values of NPP and NEE for DailyDayCent pine forests, as noted in Sect. 3.1 it was decided not to include this model's results into the pine model averages and standard deviations.

\subsubsection{Scots pine}

Similarities in the geographical variation of NEE and NPP suggests that growth dominates sequestration. The largest growth and sequestration is in central/southern Germany, Austria, northern Bulgaria and northern Spain. The smallest growth and sequestration is in high northern latitudes, Poland and southern Spain.

For growth, the largest uncertainties between models are in areas where both models have high growth, but there is a magnitude difference (central Europe and NW Spain). However, there are also areas of large uncertainty where only one 

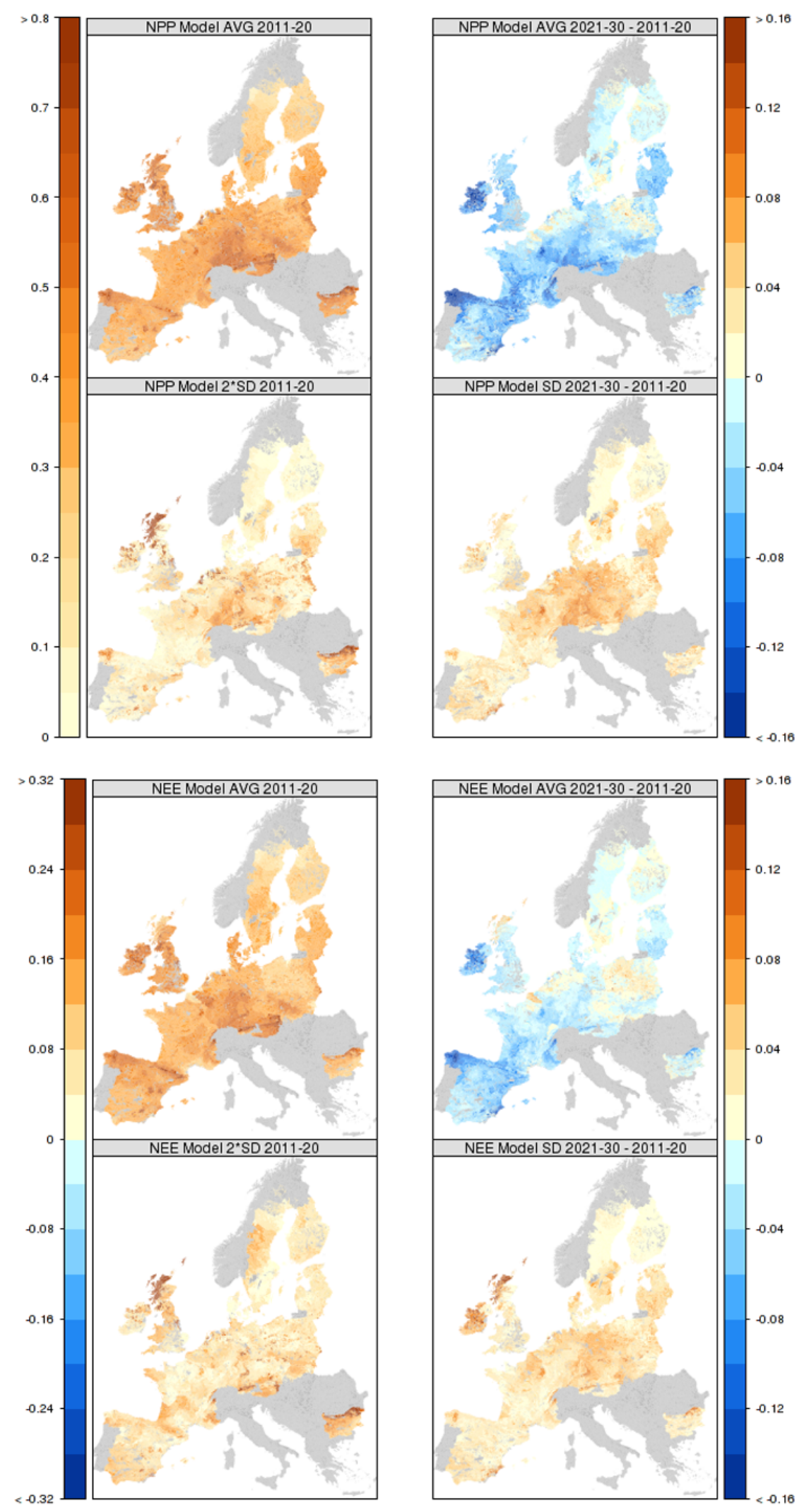

Fig. 3. NPP (top four plots) and NEE (bottom four plots) $\left(\mathrm{kg} \mathrm{C} \mathrm{m}^{-2} \mathrm{yr}^{-1}\right)$ for Scots pine. The first and third rows are averages over the models. The second and fourth rows are standard deviations (right column) or two times standard deviations (left column) over the models. The left column is the decadal average 2011-2020. The right column is the difference in decadal average 2021-2030 minus 2011-2020. 

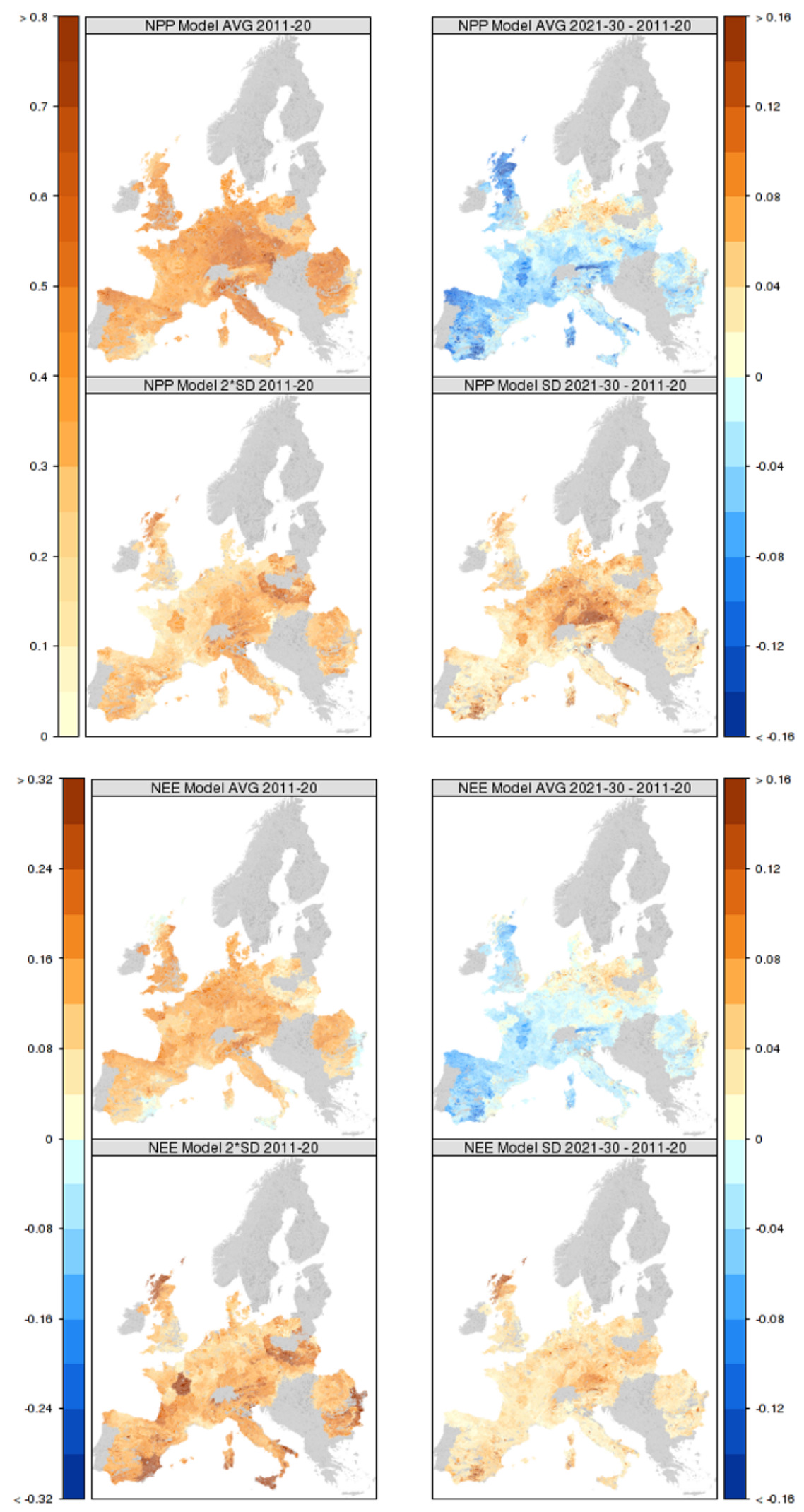

Fig. 4. NPP (top four plots) and NEE (bottom four plots) $\left(\mathrm{kg} \mathrm{C} \mathrm{m}^{-2} \mathrm{yr}^{-1}\right)$ for European beech. The first and third rows are averages over the models. The second and fourth rows are standard deviations (right column) or two times standard deviations (left column) over the models. The left column is the decadal average 2011-2020. The right column is the difference in decadal average 2021-2030 minus 2011-2020. 
Table 2. $R^{2}$ of linear regressions for NPP of Scots pine and European beech forests.

\begin{tabular}{lrrr}
\hline Scots Pine & BASFOR & LandscapeDNDC & DailyDayCent \\
\hline Precipitation & 0.04 & 0.19 & \\
Temperature & 0.12 & 0.13 & \\
Initial soil N & 0.65 & 0.02 & \\
N deposition & 0.11 & 0.12 & \\
\hline European Beech & BASFOR & LandscapeDNDC & DailyDayCent \\
\hline Precipitation & 0.08 & 0.00 & 0.04 \\
Temperature & 0.08 & 0.15 & 0.07 \\
Initial soil N & 0.16 & 0.03 & 0.00 \\
N deposition & 0.22 & 0.06 & 0.01 \\
\hline
\end{tabular}

model has high growth for example NW Scotland and Bulgaria.

The large uncertainties in the areas where there are magnitude differences in NPP are less apparent for NEE suggesting that opposing magnitude differences in soil respiration compensate for model differences in growth. The smaller interval in the uncertainty plots of NEE allows us to see a greater geographical heterogeneity in the model uncertainty although this is also affected by the inclusion of output from INTEGRATOR. Indeed greater model uncertainty over Spain is largely due to the absence of any variation in NEE in Spain in INTEGRATOR. This is due to Spain being averaged for this model, caused by a lack of more detailed spatial data.

Linear regressions can give a first indication of which drivers are most important for growth in each of the models. Linear regression for the pine NCUs (Table 2) suggests that the strongest drivers of NPP for LandscapeDNDC are precipitation, followed by temperature and nitrogen deposition. For BASFOR nitrogen is more important with temperature and $\mathrm{N}$ deposition being less important. Unlike LandscapeDNDC temperature is more important than precipitation.

The influence of NPP was found to be particularly strong for soil respiration in BASFOR $\left(R^{2}=0.86\right)$ suggesting that the NPP-respiration coupling in this model is strong for pine. For LandscapeDNDC, NPP was the largest influence on soil respiration, but the correlation was weaker $\left(R^{2}=0.44\right)$.

\subsubsection{European beech}

There are similarities with pine with highest sequestration over central and southern Germany and Austria. There are differences with greater sequestration over SE France, N Germany, Denmark and the Netherlands than for pine, but lower sequestration and growth over Poland, SE Spain and NW Scotland.

Linear regression (Table 2) suggests that unlike pine temperature is more important than precipitation for beech according to LandscapeDNDC and DailyDayCent. Whereas for BASFOR precipitation is relatively more and temperature less important for beech than for pine. BASFOR has a weaker relationship with soil $\mathrm{N}$ than for pine which may suggest that $\mathrm{N}$ is less limiting for growth in BASFOR beech.

These regression differences help explain greater model uncertainty for beech than for pine for growth and NEE. Greater uncertainty over Poland is due to differences in sensitivity to N. Differences over specific areas in northern France are due to differences in harvesting. Particularly marked are differences in NEE in more extreme climates (NW Scotland, SE Spain, Sicily, the heel of Italy and E. Romania). BASFOR and DailyDayCent have no or very low growth in dry areas of the Mediterranean and negative NEE, whereas LandscapeDNDC does not show a marked drought response in these areas.

Soil respiration in LandscapeDNDC has a larger dependence on NPP for beech than pine (NPP $R^{2}=0.77$ ) opposite to that of BASFOR (NPP $R^{2}=0.55$ ). This stronger coupling for LandscapeDNDC helps explain the lower $\mathrm{C}$ sequestration for similar growth for beech than pine noted in Sect. 3.2.

\subsection{Decadal differences in carbon sequestration}

\subsubsection{Environmental drivers and management}

Maps of temperature and precipitation and how they changed between the decades can be seen in Fig. 5. It is striking that the temperature and precipitation changes are negatively correlated, with higher precipitation and lower temperatures in central Europe and lower precipitation and higher temperatures in southern and high northern latitudes. This helps explain the small European average changes noted in Sect. 3.3.

Nitrogen deposition is higher in Eastern Europe and Italy and lower in central Europe and Germany, in particular, with $\mathrm{N}$ deposition reducing by $1.3 \%$ in pine and increasing by $2.7 \%$ in beech forests. Due to ageing and clearfelling, at $80 \mathrm{yr}$ for pine and $100 \mathrm{yr}$ for beech, the mean age of the forest has also changed between the decades with pine forests $3 \%$ older and beech forests $7 \%$ older.

\subsubsection{Scots pine}

In general, both growth and NEE decrease over time although there are significant areas such as over Poland and the Netherlands where growth and to a greater extent NEE have increased. Over Poland and the Netherlands $\mathrm{N}$ deposition has increased, leading to higher growth whereas soil respiration has reduced due to lower temperatures. The largest reduction in growth is in Ireland, where temperature and precipitation have modestly increased but $\mathrm{N}$ deposition has fallen significantly, and NW Spain where a reduction in soil N in BASFOR and LandscapeDNDC has combined with modest falls in temperature and precipitation.

As for NPP the largest uncertainty in the change in NPP is in southern Germany. To the north of this region in Belgium, the Netherlands NE Germany and northern Poland uncertainty is high for both NPP and sequestration. This is due to 


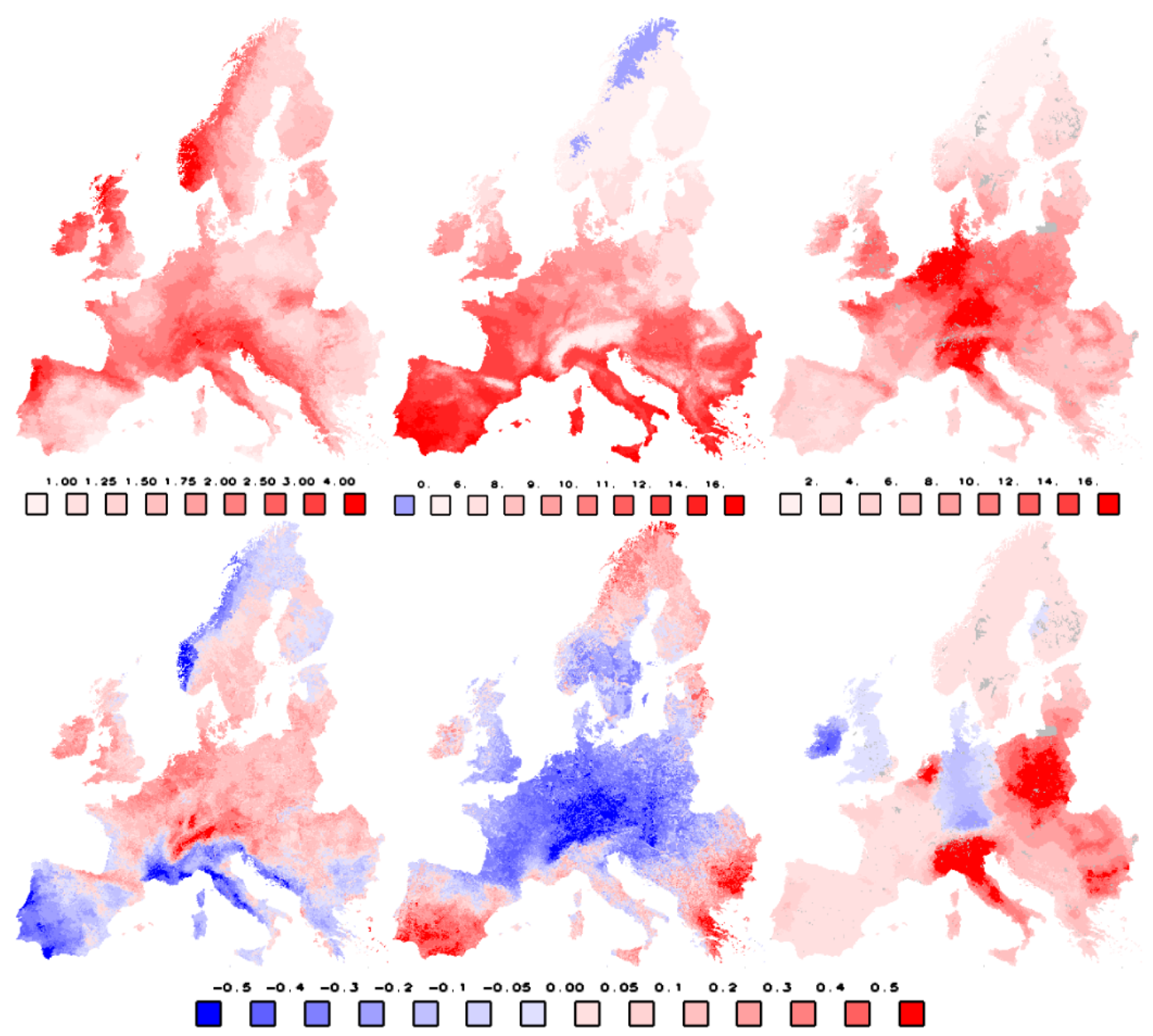

Fig. 5. The top row shows decadal average environmental drivers 2011-2020. The bottom row are differences in decadal average environmental drivers 2021-2030 minus 2011-2020. The left column is precipitation (mm day ${ }^{-1}$ ), the middle is temperature $\left({ }^{\circ} \mathrm{C}\right)$ and the right is nitrogen deposition $\left(\mathrm{kg} \mathrm{N} \mathrm{ha}^{-1} \mathrm{yr}^{-1}\right)$.

BASFOR and LandscapeDNDC having opposite responses to the decadal climatic changes. Taking an average in this area temperature was $0.8^{\circ} \mathrm{C}$ lower than the European average in the first decade and precipitation was $9 \%$ lower. In the second decade temperature fell by $0.3^{\circ} \mathrm{C}$ while precipitation increased by $11 \%$. As noted in Sect. 4.1 .1 growth in BASFOR is more sensitive to temperature than precipitation whereas LandscapeDNDC has the opposite sensitivity. Uncertainty is larger for NEE in Ireland than NPP due to the inclusion of results from INTEGRATOR which is less sensitive to changes in $\mathrm{N}$ deposition than the other two models.

\subsubsection{European beech}

For beech there is greater similarity between the change in growth and NEE than for pine. There is an area of increased growth and NEE in the Netherlands, northern Germany and Poland greater than that found for pine largely due to the inclusion of results from the DailyDayCent which similar to
LandscapeDNDC has a greater sensitivity to changes in precipitation than to temperature. However, like pine, the area where growth and sequestration have decreased is greater. This is particularly marked over the northern UK, particular areas in France (due to a lack of strong growth in recently harvested areas) and southern Spain where reduced precipitation and greater temperatures increase the already weak growth in this area due to drought.

As found before there are larger model uncertainties for beech than pine. These uncertainties are greatest over southern Germany and Austria where BASFOR and LandscapeDNDC have reduced growth and NEE, whereas DailyDayCent has strong increased growth and NEE cancelling somewhat the influence of the other models in the mean in this region. There is also greater uncertainty in southern Spain where not all models have as strong a reduction in growth as BASFOR. For NEE there are larger uncertainties over Poland where larger reductions in soil respiration in this region for LandscapeDNDC are not found for the other models. 
Table 3. $R^{2}$ of linear regressions for $\mathrm{N}_{2} \mathrm{O}$ and the logarithm of $\mathrm{N}_{2} \mathrm{O}$ of Scots pine and European beech forests.

\begin{tabular}{lrrrrrr}
\hline Scots Pine & BASFOR & $\log$ (BASFOR) & LandscapeDNDC & $\log ($ LandscapeDNDC) & DailyDayCent & INTEGRATOR \\
\hline Precipitation & 0.00 & 0.00 & 0.00 & 0.04 & 0.06 & 0.09 \\
Soil N & 0.48 & 0.35 & 0.15 & 0.17 & 0.12 & 0.04 \\
N deposition & 0.02 & 0.11 & 0.01 & 0.15 & 0.01 & 0.03 \\
NPP & 0.24 & 0.35 & 0.00 & 0.02 & 0.46 & \\
\hline European Beech & BASFOR & $\log ($ BASFOR $)$ & LandscapeDNDC & $\log$ (LandscapeDNDC) & DailyDayCent & INTEGRATOR \\
\hline Precipitation & 0.04 & 0.24 & 0.00 & 0.00 & 0.00 & 0.08 \\
Soil N & 0.35 & 0.17 & 0.15 & 0.09 & 0.00 & 0.01 \\
N deposition & 0.00 & 0.01 & 0.10 & 0.18 & 0.00 & 0.03 \\
NPP & 0.00 & 0.00 & 0.13 & 0.41 & 0.20 & \\
\hline
\end{tabular}

\section{$5 \quad \mathbf{N}_{2} \mathrm{O}$ emissions}

\subsection{Spatial variation in $\mathrm{N}_{2} \mathrm{O}$ emissions}

Maps of $\mathrm{N}_{2} \mathrm{O}$ for pine Fig. 6 show highest values in high northern latitudes SE Spain and eastern Europe with lower values in northern and western Spain, Austria, the Czech Republic and SE Germany. Model differences are largest over Sweden where INTEGRATOR has high emissions, but the other models do not. It is harder to see a clear pattern of uncertainty for the rest of Europe although there is a general tendency to have higher uncertainty where $\mathrm{N}_{2} \mathrm{O}$ emissions are higher such as in Austria, the Czech Republic and SE Germany and parts of northern Spain. In general, there appears to be less agreement between models than for carbon sequestration.

For $\mathrm{N}_{2} \mathrm{O}$ emissions in pine forests BASFOR, LandscapeDNDC and DailyDayCent have similar relationships to driving variables (Table 3 ). Soil $\mathrm{N}$ has the strongest relationship for BASFOR and LandscapeDNDC and mineral $\mathrm{N}$ has second strongest relationship for DailyDayCent. NPP has the strongest relationship for DailyDayCent and the second strongest relationship for BASFOR and by the second decade NPP is also important for LandscapeDNDC $\left(R^{2}=0.21\right)$ along with $\mathrm{N}$ deposition $\left(R^{2}=0.24\right)$. The strong relationship of $\mathrm{N}_{2} \mathrm{O}$ with NPP indicates that smaller growth leads to a smaller $\mathrm{N}$ demand from the soil (as can be seen in Sect. 3.2) shifting the balance so that more $\mathrm{N}$ is available to be emitted.

As already noted $\mathrm{N}_{2} \mathrm{O}$ emissions are higher for beech forests than pine. The pattern of highest emission is somewhat similar to that of pine forests with higher values over SE Spain, eastern regions such as Romania, Bulgaria, Slovakia and Poland although there are now also higher values over southern Germany, northern France and Italy. Similar to pine there are lower values over northern and western Spain, SW France and parts of the Alps. There is a greater discernible pattern of uncertainties for beech than pine with higher uncertainties over Austria, the Czech Republic, Eastern Germany, NW Scotland, Bulgaria, eastern Spain and southern Italy. There is a spilt in the models with BASFOR and Land-
scapeDNDC having higher emissions in central Europe and Italy than DailyDayCent and INTEGRATOR.

Similar to pine DailyDayCent emissions from beech forests have their strongest relationship with NPP (Table 3). However, for BASFOR the relationship with NPP is weaker than for pine supporting the suggestion in Sect. 4.1.2 that $\mathrm{N}$ is less limiting for growth in BASFOR beech. Similar to DailyDayCent NPP is one of the most significant factors for LandscapeDNDC. The importance of NPP increases yet further if we carry out a linear regression on $\log \left(\mathrm{N}_{2} \mathrm{O}\right)$ rather than $\mathrm{N}_{2} \mathrm{O}$ and there is also a strong relationship with carbon litter flux $\left(R^{2}=0.43\right)$. Indeed unlike BASFOR and DailyDayCent there is a positive correlation between NPP and $\mathrm{N}_{2} \mathrm{O}$ emissions. Thus, for LandscapeDNDC, $\mathrm{N}_{2} \mathrm{O}$ emissions are less sensitive to $\mathrm{N}$ limitation in the soil due to uptake and more sensitive to the $\mathrm{N}$ available to be emitted in the litter layer which is larger for beech than pine.

\subsection{Decadal differences in $\mathrm{N}_{2} \mathrm{O}$ Emissions}

The decadal change in $\mathrm{N}_{2} \mathrm{O}$ depicted in Fig. 6 and the large uncertainty can best be understood as a difference plot between BASFOR and LandscapeDNDC which generally predicted opposite responses of $\mathrm{N}_{2} \mathrm{O}$ to the environmental changes. The decadal differences in $\mathrm{N}_{2} \mathrm{O}$ were smaller for INTEGRATOR and DailyDayCent suggesting that they were less sensitive to environmental changes. This may suggest that the $\mathrm{N}$ available for emission was not greatly perturbed in these models.

For both beech and pine, LandscapeDNDC has widespread lower emissions in the second decade with spatial similarities to changes in soil nitrogen (not shown). It was noted in Sect. 3.2 that the outgoing flux of $\mathrm{N}$ in the first decade was not matched by incoming $\mathrm{N}$ to the soil. Thus, during this decade the soil was depleted of $\mathrm{N}$ so that in the second decade there was less soil $\mathrm{N}$ available to be emitted. A linear regression of changes in $\mathrm{N}_{2} \mathrm{O}$ against changes in soil nitrogen suggest that they are highly correlated $\left(R^{2}=0.67\right)$. This indicates that the lower $\mathrm{N}_{2} \mathrm{O}$ emitted in the second decade is related to depleted soil $\mathrm{N}$. 

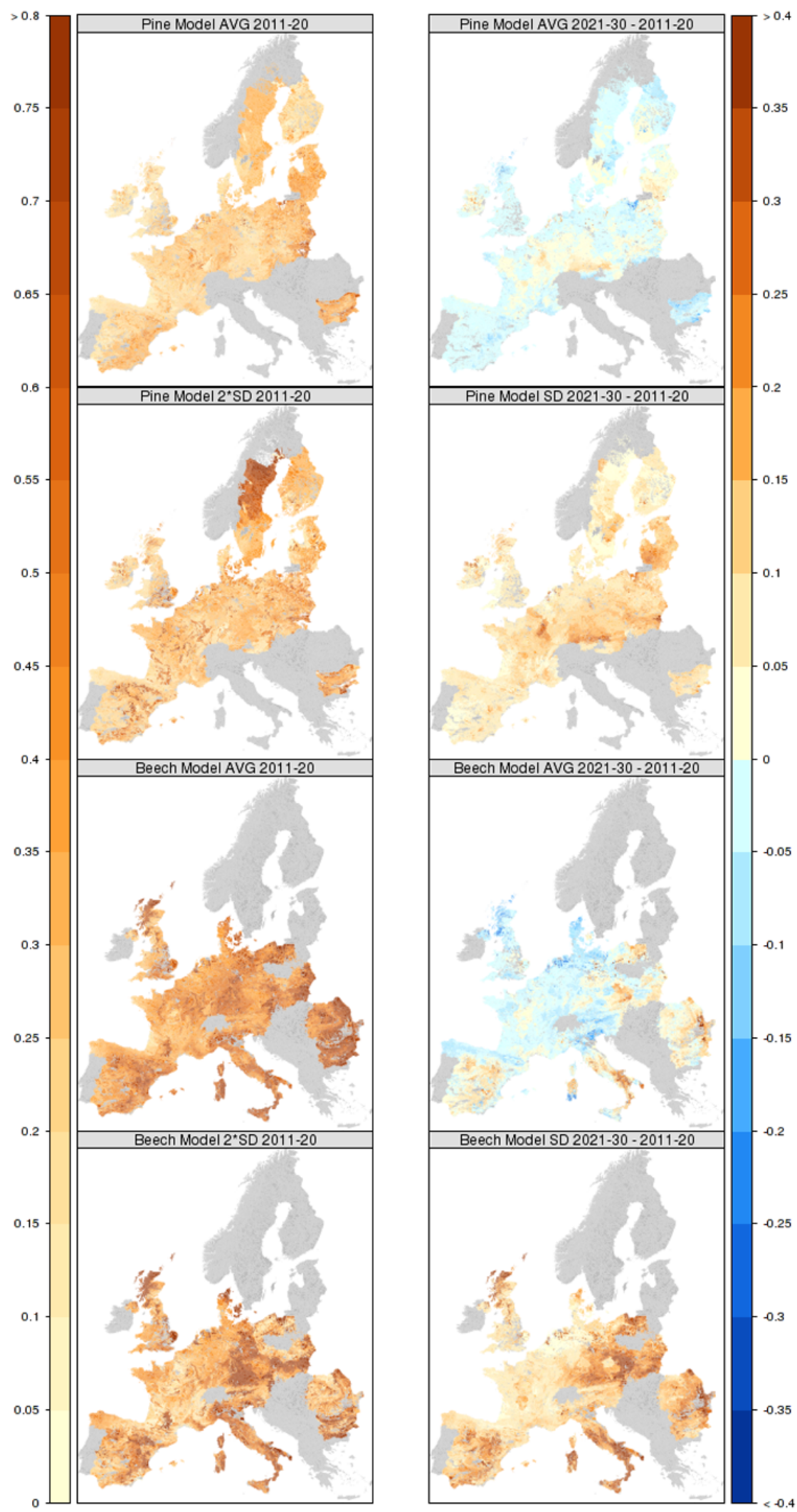

Fig. 6. $\mathrm{N}_{2} \mathrm{O}\left(\mathrm{kg} \mathrm{Nha}^{-1} \mathrm{yr}^{-1}\right)$ for Scots pine and European beech. The first and third rows are averages over the models. The second and fourth rows are standard deviations (right column) or two times standard deviations (left column) over the models. The left column is the decadal average 2011-2020. The right column is the difference in decadal average 2021-2030 minus 2011-2020. 
In BASFOR soil $\mathrm{N}$ is also out of balance in the first decade, but to a lesser extent and $\mathrm{N}_{2} \mathrm{O}$ emissions generally increase across Europe for pine and to a lesser extent for beech. In addition, comparing the difference maps of NPP with those of $\mathrm{N}_{2} \mathrm{O}$ (not shown) suggested that they may be correlated. Indeed, linear regressions would suggest a significant relationship $\left(R^{2}=0.24\right)$ between the change in $\log \mathrm{N}_{2} \mathrm{O}$ and NPP. This is perhaps unsurprising given the relatively strong relationship between $\mathrm{N}_{2} \mathrm{O}$ emissions and NPP identified for BASFOR above.

\section{Discussion}

\subsection{Average results for Europe}

This study was concerned with quantifying the greenhouse balance of European forests considering not only $\mathrm{CO}_{2}$, but also $\mathrm{N}_{2} \mathrm{O}$. Taking the average over the models we found a European average carbon sink for 2011-2020 of $0.160 \pm 0.020 \mathrm{kgC} \mathrm{m}^{-2} \mathrm{yr}^{-1}$ for pine (excluding the large DailyDayCent pine $\mathrm{C}$ sink) and $0.138 \pm 0.062 \mathrm{kgC} \mathrm{m}^{-2} \mathrm{yr}^{-1}$ for beech. This is comparable to the values for 'ecological sites' $\left(0.200 \pm 0.052 \mathrm{kgC} \mathrm{m}^{-2} \mathrm{yr}^{-1}\right)$ and national forest inventories $\left(0.160 \pm 0.020 \mathrm{kgC} \mathrm{m}^{-2} \mathrm{yr}^{-1}\right)$ found in Luyssaert et al. (2010) (henceforth L10). In the remainder of this discussion, we will refer to "ecological sites" as termed in L10 as observational sites and will refer to national forest inventories from L10 as just inventories. In addition, we found a European average $\mathrm{N}_{2} \mathrm{O}$ source for 20112020 of $0.285 \pm 0.125 \mathrm{kgN} \mathrm{ha}^{-1} \mathrm{yr}^{-1}$ for pine and $0.575 \pm$ $0.105 \mathrm{kgNha}^{-1} \mathrm{yr}^{-1}$ for beech. This is comparable to the range of 0.55 to $0.62 \mathrm{kgNha}^{-1} \mathrm{yr}^{-1}$ found for all forest species in the modelling and observational study of European $\mathrm{N}_{2} \mathrm{O}$ reported in Kesik et al. (2005). Given that the model used in that study (PnET-N-DNDC), is closely related to LandscapeDNDC, it is perhaps unsurprising that we found similar values. We found that the sink through uptake of $\mathrm{CO}_{2}$ was dominant over the source of $\mathrm{N}_{2} \mathrm{O}$ by a factor 18 (pine) and 8 (beech). This is consistent with the prevailing assertion that age structure and management practices in Europe are continually changing such that forests overall are currently sequestering carbon (Nabuurs et al., 2003) and that $\mathrm{C}$ sequestration dominates over forest soil $\mathrm{N}_{2} \mathrm{O}$ emissions (De Vries et al., 2011a). It was also found that there was a greater imbalance between tree growth and litter fall than between litter flux into the soil and respiration. Hence, more of the carbon sink is sequestered by the trees than the soil. This is consistent with L10 who found an 78/22\% split between carbon sequestered by the trees and the soil.

LandscapeDNDC and DailyDayCent had larger carbon sequestration for pine than beech trees whereas INTEGRATOR and BASFOR showed the reverse. The N- and C-budgets presented in Sect. 3.2 help explain these differences. For BASFOR a more favourable climate and less $\mathrm{N}$ limitation for beech contributed to higher NPP. For LandscapeDNDC the higher litter flux for beech than pine led to higher soil respiration and lower NEE. Indeed litter flux and soil respiration were generally higher for beech forests which is perhaps unsurprising given the seasonal defoliation in deciduous forests.

It was also found that $\mathrm{N}_{2} \mathrm{O}$ emissions were larger from beech forests than pine which is in agreement with results from field observations (e.g., Butterbach-Bahl et al., 2011). This is likely to be related to higher inputs of nitrogen to the soil from nitrogen deposition and litter in beech forests and differences in soil moisture during the dormant period (Butterbach-Bahl et al., 2002). In contrast, emissions of NO were found to be higher in pine than beech forests for LandscapeDNDC, but not for BASFOR. This is consistent with Pilegaard et al. (2006) who found higher emissions from coniferous forests than deciduous forests. They suggested that nitrification favouring $\mathrm{NO}$ emissions is more likely from coniferous forests, where soil moisture is lower and litter is thick and well aerated, and denitrification favouring $\mathrm{N}_{2} \mathrm{O}$ emissions is more likely from deciduous forests with a more compact moist litter layer.

Since both L10 and the first decade of this study, while not for the same years, are both close to present day we consider that they can be usefully compared. In the following discussion, Table 3 from L10 will be compared with our Table 4. For NPP the values for the models in this study are generally lower than those for the models in L10. However, this is consistent with the lower NPP value for the only model in L10 to include the influence of $\mathrm{N}$ (BIOME-BGC) and is consistent with the assertion that European forests are $\mathrm{N}$ limited. For pine, BASFOR is closest to the observational sites and inventory values. As already noted DailyDayCent pine values are approximately double of those both in this study and in L10. For beech, BASFOR had higher and LandscapeDNDC and DailyDayCent lower values than those found in inventories and observational sites. For soil respiration, the model values here are generally significantly lower than those for models in L10. The difference is due to a lack of management in the L10 models since managed removal of carbon cannot be respired from the soil. Thus, NEE values for the models in this study are largely higher than those in L10. In general, the values of carbon sequestration found here are similar to the range $0.16-0.20 \mathrm{kgC} \mathrm{m}^{-2} \mathrm{yr}^{-1}$ found in L10 for inventories and observational sites. The exceptions are LandscapeDNDC and DailyDayCent beech which had lower values and DailyDayCent pine which had a far higher value. L10 calculate the split in NPP between soil respiration and NEE for the inventories, observational sites and each of the models in their study. These values are given in Table 3 of their paper and will be compared with the values for the models in this study. For pine, BASFOR has a 70/30 split which is closer to the split found in L10 for observational sites than inventories (65/35) whereas LandscapeDNDC and DailyDayCent are close to a 50/50 split. For beech, BASFOR 
Table 4. European area weighted average values for Scots pine and European beech forests $\left(\mathrm{kg} \mathrm{C} \mathrm{m}^{-2} \mathrm{yr}^{-1}\right)$ averaged over years $2011-2020$. $\mathrm{N}_{2} \mathrm{O}$ has units $\mathrm{kg} \mathrm{Nha}^{-1} \mathrm{yr}^{-1}$. Missing values in the table are where a model output was unavailable.

\begin{tabular}{lrrrrrr}
\hline Scots Pine & BASFOR & LandscapeDNDC & DailyDayCent & INTEGRATOR & Mean & Standard Deviation \\
\hline NPP & 0.465 & 0.341 & 0.962 & & 0.589 & 0.329 \\
Soil Respiration & 0.326 & 0.162 & 0.463 & & 0.317 & 0.151 \\
Exported C & 0.090 & 0.066 & 0.216 & & 0.124 & 0.081 \\
Litter C & 0.325 & 0.151 & & & 0.238 & 0.123 \\
$\mathrm{NEE}$ & 0.139 & 0.179 & 0.499 & 0.161 & 0.244 & 0.170 \\
$\mathrm{~N}_{2} \mathrm{O}$ & 0.146 & 0.329 & 0.227 & 0.438 & 0.285 & 0.126 \\
\hline European Beech & $\mathrm{BASFOR}$ & LandscapeDNDC & DailyDayCent & INTEGRATOR & Mean & Standard Deviation \\
\hline $\mathrm{NPP}$ & 0.659 & 0.332 & 0.354 & & 0.448 & 0.183 \\
Soil respiration & 0.475 & 0.263 & 0.250 & & 0.329 & 0.126 \\
Exported C & 0.153 & 0.082 & 0.062 & & 0.099 & 0.048 \\
Litter C & 0.478 & 0.237 & & & 0.357 & 0.170 \\
$\mathrm{NEE}$ & 0.184 & 0.068 & 0.103 & 0.195 & 0.138 & 0.062 \\
$\mathrm{~N}_{2} \mathrm{O}$ & 0.556 & 0.712 & 0.574 & 0.458 & 0.575 & 0.105 \\
\hline
\end{tabular}

and DailyDayCent are close to a 70/30 split consistent with observational sites, whereas LandscapeDNDC has an 80/20 split which is closer to a model (Modified LPJ) in L10 which included management. Whilst exported carbon values themselves are either slightly higher or not dissimilar to those of L10 the percentage of NPP that is exported is closer to $20 \%$ for pine and $17-25 \%$ for beech, whereas inventory and ecological site percentages are between 10-16\%. This higher fraction of NPP exported partially explains the lower percentage of soil respiration for LandscapeDNDC and DailyDayCent pine. For BASFOR pine and LandscapeDNDC and DailyDayCent beech the higher fraction of exported $C$ is offset by a higher percentage of NPP which becomes litter than the $50 \%$ and $60 \%$ found for inventories and observational sites indicated in Ciais et al. (2008). In general, the percentage of NPP which is sequestered in the models in this study which included the influence of $\mathrm{N}$ and management are closer to those for inventories and observational sites than the models in L10. This supports the conclusion in L10 that management practises and $\mathrm{N}$ deposition rather than changes in $\mathrm{CO}_{2}$ and climate control the carbon sequestration ratio (NEE/NPP).

\subsection{Interaction of geographical and model differences with environmental factors}

We found that carbon sequestration was generally highest in central/southern Germany and Austria and northern Spain with lower values in N. Scandinavia, Poland and southern Spain. We found that the geographical variation in NPP was more important than soil respiration for this. This is consistent with Ciais et al. (2008) who found a linear relationship between carbon sequestration and growth.

There were significant differences between the geographical variability of growth and NEE given by the models and, thus, giving significant uncertainty in model predictions. The uncertainty was larger for beech than for pine forests although this will be at least partly due to the inclusion of DailyDayCent in beech, but not pine results.

Uncertainty tended to be larger where growth was greatest, as might be expected, due mainly to magnitude differences which are related to differences in the models sensitivity to driving variables. For example BASFOR was more sensitive to soil $\mathrm{N}$ than LandscapeDNDC. Compensating model differences in soil respiration led to lower NEE uncertainty in NW Spain, southern Germany and Austria than might have been expected from NPP.

Uncertainties were also greater in areas where initial soil $\mathrm{N}$ was particularly high, perhaps unrealistically so. For example, NW Scotland, NW Spain and Bulgaria where growth was high in BASFOR and significantly lower in LandscapeDNDC since BASFOR has a greater sensitivity to soil $\mathrm{N}$.

Similarly uncertainty was larger in regions where driving variables were very low for example in the low rain areas of SE Spain, Sardinia, the heel of Italy and E. Romania the models responded differently to low soil water conditions. BASFOR and DailyDayCent beech forests had no or very low growth and negative NEE compared to LandscapeDNDC and INTEGRATOR.

In some areas where uncertainties were high, deficiencies in a particular model were important. For example larger uncertainties in Spain were in part due to homogeneous carbon sequestration in INTEGRATOR.

There was considerable uncertainty about the geographical location of $\mathrm{N}_{2} \mathrm{O}$ emissions. Two of the models, BASFOR and LandscapeDNDC, had largest emissions in central Europe where nitrogen deposition and soil nitrogen were largest. There was more similarity between the models in the sensitivities of geographical variations of $\mathrm{N}_{2} \mathrm{O}$ to drivers. For BASFOR and LandscapeDNDC the largest driver was soil 
nitrogen and for BASFOR, LandscapeDNDC and DailyDayCent NPP was also important. Indeed, $\mathrm{N}_{2} \mathrm{O}$ emissions had a negative spatial relationship with NPP for BASFOR and DailyDayCent because $\mathrm{N}$ uptake from the soil reduced the $\mathrm{N}$ available to be emitted. For LandscapeDNDC, NPP was also important for $\mathrm{N}_{2} \mathrm{O}$ emissions, but the relationship was positive so that where growth was higher the litter flux of $\mathrm{N}$ to the soil was greater providing more available $\mathrm{N}$ for emission.

\subsection{Geographical and species differences in response to environmental changes}

Of particular interest in this study was locations in which we expect environmental changes to cause the largest changes in forest productivity, carbon sequestration and greenhouse gas balance. In addition, environmental drivers which would be the main cause of those changes. It was found that changes in carbon sequestration were dominated by NPP. This is consistent with what was found above.

No overall driver dominated changes in NPP with precipitation, temperature, nitrogen deposition and management (through clearfelling), all being significant factors.

Environmental changes had the largest impact where environmental drivers had previously been low, limiting growth in that area. For example, in regions where precipitation was below average (northern Germany and Poland), an increase led to increased growth in pine in LandscapeDNDC. Where soil $\mathrm{N}$ was lower and so limiting, for example, in Poland an increase in nitrogen deposition was found to increase growth. Where precipitation decreased in an already dry area there was a threshold response from beech forests in BASFOR and DailyDayCent, with growth collapsing, for example, in dry southern areas of Europe such as SE Spain, Sicily, Sardinia, southern tip of Italy and eastern fringes of Romania/Bulgaria.

Growth was also particularly affected where there was a change in an environmental factor that was larger, dominating the effect of others such as decreased temperature which reduced growth in BASFOR and in LandscapeDNDC beech in central Europe. In regions where other factors, such as precipitation and nitrogen deposition, were also changing the impact was reduced or even reversed (for example, in Belgium, the Netherlands, northern Germany and Poland). Indeed identification of key drivers from spatial patterns of forest dynamics is hampered by the fact that many variables covary at the European scale. Climatic variables are correlated with each other and to some extent with $\mathrm{N}$ deposition as well, with the lowest values of deposition being found in the northernmost, coldest regions. Likewise, soil $\mathrm{N}$-content reflects to some extent the past history of N-deposition, although that causal relationship is likely important only in areas where previously both deposition and soil fertility were extremely low, such as Scandinavia (Hyvönen et al., 2008).

More modest changes in environmental variables could also have a larger impact where they acted in concert. For example, the large decrease in growth in LandscapeDNDC pine forests in northern Spain was due to the combined effect of reductions in temperature, precipitation and soil nitrogen.

Model uncertainty about responses to changes in environmental drivers was important since these were large relative to the changes being predicted so we need to be cautious about taking these model results as future predictions. As already discussed in Sect. 6.2, a significant reason for model differences was differences in the sensitivities of the models to changes in environmental drivers. For example, growth in BASFOR pine forests had a greater sensitivity to temperature than precipitation and the opposite for beech forests whereas LandscapeDNDC had the reverse. As discussed, above this was particularly important for model uncertainty in Belgium, the Netherlands, northern Germany and Poland and in dry S. Spain, Sardinia and the heel of Italy. Differences in model sensitivity to changes in $\mathrm{N}$ deposition also led to uncertainties in Ireland. Uncertainties in specific regions in France were due to DailyDayCent and INTEGRATOR having different harvesting than the other models.

Similar to Sect. 6.2 compensating model differences in soil respiration led to less uncertainty in Belgium, the Netherlands, northern Germany and Poland than might have been expected from growth differences. However, where respiration had decreased due to reduced soil carbon which had been respired in the first decade by LandscapeDNDC in NW Scotland and Poland, but not in the other models NEE model uncertainty increased.

\subsection{Sensitivity of different biogeochemical processes to environmental change}

We were also interested in which parts of the nitrogen and carbon balance were most perturbed and, thus, contributed most to changes in carbon sequestration and greenhouse gas balance. The largest sensitivity to decadal differences in the trees was NPP. This was accompanied by changes in nitrogen uptake from the soil, which was responsible for the largest change in soil nitrogen balance. Whilst there were also reductions in litter flux and soil respiration, these were more modest suggesting that they are less sensitive to environmental change. The exception to this was where NPP was already very low due to low soil water availability leading to depletions in soil carbon and a larger reduction in soil respiration to restore the soil $\mathrm{C}$ balance. Consistent with the geographical variations in $\mathrm{N}_{2} \mathrm{O}$ discussed above, we found that areas where decadal NPP decreased in BASFOR changed the soil $\mathrm{N}$ balance through reduced uptake so that more nitrogen was available to be emitted. Thus, $\mathrm{N}_{2} \mathrm{O}$ emissions increased as growth decreased. In LandscapeDNDC there was a general reduction in emissions in the second decade after large emissions due to a larger soil $\mathrm{N}$ imbalance in the first decade. 


\subsection{Evaluation of methodology and outlook to future work}

The tendency for soil nitrogen and, to a lesser extent, carbon to be more out of balance in the first decade was found for pine forests in BASFOR and in both forests in LandscapeDNDC. This is likely due to imbalances between soil and tree initialisations. As this imbalance decreases during the model run (spinup) this creates a spurious factor in the time evolution. This was found to be particularly significant for $\mathrm{C}$ in LandscapeDNDC beech in Poland and for N in LandscapeDNDC and BASFOR in the NW corner of Spain, where the imbalance was largest, affecting the GHG balance in these areas. For $\mathrm{N}_{2} \mathrm{O}$ reduced fluxes in the second decade were related to soil nitrogen changes, but not changes in nitrogen uptake and growth. Likewise larger reductions in soil respiration in LandscapeDNDC were not related to reductions in litter flux and growth, but were instead found to be more consistent with changes due to soil spinup. This suppressed the sensitivity of NEE to decadal change in LandscapeDNDC. The issue of spinup in models is not a new one (Yeluripati et al., 2009), but its effects need to be recognised so that false interpretations are not made and where possible reduced. Whilst one solution is to initialise with tree data and to run the model for a number of years to allow the soil to come into balance, this is not ideal since information in the soil data will be lost. A better solution would be to calibrate the initial values of the model to both the initial tree and soil data at each site where the model is run. However, where many thousands of sites are computed, as in this study, such a calibration may not be practical.

The analysis in this study relied mainly on simple linear regressions. This is despite our understanding that many forest processes are likely to be nonlinear and as discussed above are affected by covarying environmental drivers. Whilst looking for linear relationships is a useful first step, model sensitivity studies varying the environmental drivers across Europe and analysing the responses will allow a deeper nonlinear analysis and understanding of the important underlying mechanisms.

In their study, L10 highlighted a number of factors which they identified as being potentially important for future growth in forests which have not been considered in this study. They suggested that factors such as management induced increases in fertility of soils, forest area expansion, as well as changes to more productive species such as Sitka spruce will contribute to increased growth. However, factors such as limitation in nutrients, increases in ozone concentration, climate change induced changes in species composition, increased frequency of insect outbreaks (Aber et al., 1998; Brumme and Khanna, 2008), increased frequency and intensity of forest fires will reduce growth. Such factors should be included in a future studies if our uncertainty about the future contribution of forests to the greenhouse gas balance is to be further reduced.
Uncertainty in model structure has been considered in this study through the use of four different forest models. Whilst the models in this study are well known and have been evaluated in many previous studies their application has generally been to individual forest sites rather than the whole of Europe. Indeed only one model was specifically recalibrated for use across Europe and even this was only against a number of observational sites which may or may not be a good representation of the whole of Europe. It is perhaps then unsurprising that model differences and, hence, uncertainty was found to be high. This is our current state of $\mathrm{C}$ - and $\mathrm{N}$-cycle forest modelling in Europe and this study had been able to make a first attempt at quantifying this uncertainty and highlighting possible reasons for the model differences found. While some of the differences will be due to model structural differences and, therefore, reflect our current uncertainty about how best to model forest processes some of the uncertainty could be reduced by improving the parameterisation of the models for use across Europe. This could be aided by use of increasing available remote-sensing data which may have greater errors, but can be usefully represented in calibration techniques which allow for inclusion of observational uncertainty such as Bayesian calibration.

\section{Conclusions}

In recent years there has been considerable activity aiming to quantify the present and future contributions of forests to the GHG balance of Europe. Indeed there has been considerable controversy over the importance of nitrogen for this balance. Our study is one of the first in which $\mathrm{N}$ effects, thinning and harvesting are included in a range of models, ranging from simple to complex.

- This study found a European average carbon sink for 2011-2020 of $0.160 \pm 0.020 \mathrm{kgC} \mathrm{m}^{-2} \mathrm{yr}^{-1}$ for Scots pine and $0.138 \pm 0.062 \mathrm{kgC} \mathrm{m}^{-2} \mathrm{yr}^{-1}$ for European beech. The European average $\mathrm{N}_{2} \mathrm{O}$ source for 20112020 was $0.285 \pm 0.125 \mathrm{kgN} \mathrm{ha}^{-1} \mathrm{yr}^{-1}$ for Scots pine and $0.575 \pm 0.105 \mathrm{kgN} \mathrm{ha}^{-1} \mathrm{yr}^{-1}$ for European beech.

- The GHG gas balance of forests was a sink with the uptake of $\mathrm{CO}_{2}$ being dominant over the source of $\mathrm{N}_{2} \mathrm{O}$ by a factor 18 (pine) and 8 (beech) and the sink of $\mathrm{C}$ in the trees larger than that for the soil.

- The models disagreed about whether pine or beech sequestered more carbon, with differences in growth rate dominating this.

- Carbon sequestration was highest in central Europe and lowest in high northern latitudes and southern Spain. This geographical variation was primarily determined by spatial variation in tree growth rate.

- There were differences between the models and species about which weather variables accounted the most for 
geographical variation in growth. Some models identified precipitation as the main weather driver behind spatial variation in Scots pine with temperature driving the variation in beech. Other models had the opposite sensitivity.

- Most of the models were sensitive to soil N, but there was disagreement about whether Scots pine or European beech forests were more sensitive to nitrogen availability.

- No single environmental driver dominated the response to changes between the decades 2011-2020 and 20212030. Growth was found to change more than respiration. Forest growth was found to be most sensitive to change in environmental drivers in those parts of Europe where the drivers were limiting growth, where changes were particularly large or where changes acted in concert.

- In particular, some models were sensitive to modest changes in precipitation while others had a threshold response to very low soil water content due to low precipitation. European beech forests were found to be more vulnerable to drought than Scots pine although Scots pine forests were more sensitive to more modest changes in precipitation.

- $\mathrm{N}_{2} \mathrm{O}$ emissions from soil were larger for European beech forests than Scots pine while NO emissions showed the reverse. This is likely to be due to differences in moisture content of the litter layer and differences in litter fall by Scots pine and European beech.

- Soil $\mathrm{N}$ and atmospheric deposition were found to be important for $\mathrm{N}_{2} \mathrm{O}$ emissions from soils in most of the models. NPP was also important either through limiting the $\mathrm{N}$ available to be emitted or in the opposite sense by leading to enhanced litter fall and thereby increasing the $\mathrm{N}$ available for emission.

- There were large differences found between the model predictions. Model uncertainty was greater for European beech than Scots pine forests and for $\mathrm{N}_{2} \mathrm{O}$ emissions than for carbon sequestration. Differences in the sensitivity of the models to environmental drivers can help explain these uncertainties. For prediction at the European scale, differences between models may be reduced if data with good spatial coverage, such as from remote sensing, are used to calibrate each model.

Acknowledgements. This work was part of the NitroEurope Integrated Project, funded under the EC 6th Framework Programme for Research and Technological Development (Contract 017841). The work was also part financed by the EU FP7 project GHG-Europe (contract no. 244122). David Cameron would like to acknowledge the use of surface level winds and vapour pressure from the Integrated Project Water and Global Change (WATCH, 2007-2011) project http://www.eu-watch.org/. in the calibration of BASFOR. We would like to thank the reviewers for helping to improve this paper.

Edited by: P. Cellier

\section{References}

Aber, J., McDowell, W., Nadelhoffer, K., Magill, A., Berntson, G., Kamakea, M., McNulty, S., Currie, W., Rustad, L., and Fernandez, I.: Nitrogen saturation in temperate forest ecosystems, BioScience, 48, 921-934, 1998.

Amann, M., Asman, W., Bertok, I., Cofala, J., Heyes, C., Klimont, Z., Schöpp, W., and Wagner, F.: Cost-effective emission reductions to meet the environmental targets of the Thematic Strategy on Air Pollution under different greenhouse gas constraints, NEC Scenario Analysis Report, Tech. Rep. 5, IIASA, Laxenberg, Austria, 2007.

Baker, T. R., Phillips, O. L., Malhi, Y., Almeida, S., Arroyo, L., Di Fiore, A., Erwin, T., Higuchi, N., Killeen, T. J., Laurance, S. G., Laurance, W. F., Lewis, S. L., Monteagudo, A., Neill, D. A., Núñez Vargas, P., Pitman, N. C. A., Silva, J. N. M., and Vásquez Martínez, R.: Increasing biomass in Amazonian forest plots, Philosophical Transactions of the Royal Society of London, Series B: Biological Sciences, 359, 353-365, doi:10.1098/rstb.2003.1422, 2004.

Bloemerts, M. and De Vries, W.: Relationships between nitrous oxide emissions from natural ecosystems and environmental factors, Alterra-rapport, 1853, Alterra, Wageningen, 2009.

Brumme, R. and Khanna, P. K.: Ecological and site historical aspects of $\mathrm{N}$ dynamics and current $\mathrm{N}$ status in temperate forests, Glob. Change Biol., 14, 125-141, 2008.

Butterbach-Bahl, K., Gundersen, P., Ambus, P., Augustin, J., Beier, C., Boeckx, P., Dannenmann, M., Gimeno, B. S., Rees, R. M., Smith, K. A., Stevens, C., Vesala, T., and ZechmeisterBoltenstern, S.: Nitrogen processes in terrestrial ecosystems, in: The European nitrogen assessment: sources effects, and policy perspectives, edited by: Sutton, M. A., Howard, C. M., Erisman, J. W., Billen, G., Bleeker, A., Grennfeldt, P., Van Grinsen, H., and Grozetti, B., Cambridge University Press, Cambridge, 99125, 2011.

Butterbach-Bahl, K., Rothe, A., and Papen, H.: Effect of tree distance on $\mathrm{N}_{2} \mathrm{O}$ - and $\mathrm{CH}_{4}$-fluxes from soils in temperate forest ecosystems, Plant Soil, 240, 91-103, 2002.

Cannell, M. G. R.: World forest biomass and primary production data, Academic Press, 1982.

Carter, T. R.: General guidelines on the use of scenario data for climate impact and adaption assessment, Version 2, Tech. Rep., Task Group on Data and Scenario Support for Impact and Climate Assessment (TGICA), Intergovernmental Panel on Climate Change, 2007.

Ciais, P., Schelhaas, M. J., Zaehle, S., Piao, S. L., Cescatti, A., Liski, J., Luyssaert, S., Le-Maire, G., Schulze, E.-D., Bouriaud, O., Freibauer, A., Valentini, R., and Nabuurs, G. J.: Carbon accumulation in European forests, Nature Geosci., 1, 425-429, doi:10.1038/ngeo233, 2008. 
COM: Directive of the European Parliament and of the Council on the Promotion of the Use of Energy from Renewable Sources, Commission of the European Communities, Brussels, Belgium, 2008.

De Vries, W. and Posch, M.: Modelling the impact of nitrogen deposition, climate change and nutrient limitations on tree carbon sequestration in Europe for the period 1900-2050, Environ. Pollut., 159, 2289-2299, 2011.

De Vries, W., Solberg, S., Dobbertin, M., Sterba, H., Laubhann, D., Van Oijen, M., Evans, C., Gundersen, P., Kros, J., Wamelink, G., Reinds, G., and Sutton, M.: The impact of nitrogen deposition on carbon sequestration by European forests and heathlands, Forest Ecol. Manag., 258, 1814-1823, doi:10.1016/j.foreco.2009.02.034, 2009.

De Vries, W., Kros, J., Reinds, G. J., and Butterbach-Bahl, K.: Quantifying impacts of nitrogen use in European agriculture on global warming potential, Curr. Opin. Environ. Sustain., 3, 291302, doi:10.1016/j.cosust.2011.08.009, 2011a.

De Vries, W., Leip, A., Reinds, G., Kros, J., Lesschen, J., and Bouwman, A.: Comparison of land nitrogen budgets for European agriculture by various modeling approaches, Environ. Pollut., 159, 3254-3268, doi:10.1016/j.envpol.2011.03.038, 2011 b.

Dentener, F., Drevet, J., Lamarque, J. F., Bey, I., Eickhout, B., Fiore, A. M., Hauglustaine, D., Horowitz, L. W., Krol, M., Kulshrestha, U. C., Lawrence, M., Galy-Lacaux, C., Rast, S., Shindell, D., Stevenson, D., Van Noije, T., Atherton, C., Bell, N., Bergman, D., Butler, T., Cofala, J., Collins, B., Doherty, R., Ellingsen, K., Galloway, J., Gauss, M., Montanaro, V., Müller, J. F., Pitari, G., Rodriguez, J., Sanderson, M., Solmon, F., Strahan, S., Schultz, M., Sudo, K., Szopa, S., and Wild, O.: Nitrogen and sulfur deposition on regional and global scales: A multimodel evaluation, Glob. Biogeochem. Cy., 20, GB4003, doi:10.1029/2005GB002672, 2006.

Dieleman, W. I. J., Luyssaert, S., Rey, A., De Angelis, P., Barton, C. V. M., Broadmeadow, M. S. J., Broadmeadow, S. B., Chigwerewe, K. S., Crookshanks, M., Dufrêne, E., Jarvis, P. G., Kasurinen, A., Kellomäki, S., Le Dantec, V., Liberloo, M., Marek, M., Medlyn, B., Pokorný, R., Scarascia-Mugnozza, G., Temperton, V. M., Tingey, D., Urban, O., Ceulemans, R., and Janssens, I. A.: Soil $\mathrm{N}$ modulates soil $\mathrm{C}$ cycling in $\mathrm{CO}_{2}$-fumigated tree stands: a meta-analysis, Plant, Cell Environ., 33, 2001-2011, doi:10.1111/j.1365-3040.2010.02201.x, 2010.

FAOSTAT: ForesStat. Roundwood production quantity, FAO statistics division, http://faostat.fao.org/site/626/default.aspx\#ancor, 2009.

Friedlingstein, P., Fung, I., Holland, E., John, J., Brasseur, G., Erickson, D., and Schimel, D.: On the contribution of $\mathrm{CO}_{2}$ fertilization to the missing biospheric sink, Glob. Biogeochem. Cy., 9, 541-556, doi:10.1029/95GB02381, 1995.

Grace, J.: Understanding and managing the global carbon cycle., J. Ecol., 189-202, 2004.

Grote, R., Kiese, R., Gruenwald, T., Ourcival, J.-M., and Granier, A.: Modelling forest carbon balances considering tree mortality and removal, Agr. Forest Meteorol., 151, 644-644, 2011.

Gundersen, P., Schmidt, I. K., and Raulund-Rasmussen, K.: Leaching of nitrate from temperate forests - effects of air pollution and forest management, Environ. Rev., 14, 1-57, doi:10.1139/a05$015,2006$.
Gupta, S. C. and Larson, W. E.: Estimating soil water retention characteristics from particle size distribution, organic matter percent, and bulk density, Water Resources Research, 15, 1633-1635, 1979.

Haas, E., Klatt, S., Fröhlich, A., Werner, C., Kiese, R., Grote, R., and Butterbach-Bahl, K.: LandscapeDNDC: A process model for simulation of biosphere-atmosphere-hydrosphere exchange processes at site and regional scale, Landscape Ecology, 1-22, doi:10.1007/s10980-012-9772-x, 2012.

Hengl, T., Heuvelink, G., and Stein, A.: A generic framework for spatial prediction of soil variables based on regression-kriging, Geoderma, 120, 75-93, 2004.

Hyvönen, R., Persson, T., Andersson, S., Olsson, B., Ågren, G., and Linder, S.: Impact of long-term nitrogen addition on carbon stocks in trees and soils in northern Europe, Biogeochemistry, 89, 121-137, doi:10.1007/s10533-007-9121-3, 2008.

Kahle, H.-p., Karjalainen, T., Schuck, A., Ågren, G. I., and Kellomaki, S.: Causes and Consequences of Forest Growth Trends in Europe: Results of the Recognition Project, Brill Academic Publication, 2008.

Kauppi, P. E., Mielikäinen, K., and Kuusela, K.: Biomass and carbon budget of European forests, 1971 to 1990, Science, 256, 7074, 1992.

Kesik, M., Ambus, P., Baritz, R., Brüggemann, N., ButterbachBahl, K., Damm, M., Duyzer, J., Horváth, L., Kiese, R., Kitzler, B., Leip, A., Li, C., Pihlatie, M., Pilegaard, K., Seufert, S., Simpson, D., Skiba, U., Smiatek, G., Vesala, T., and ZechmeisterBoltenstern, S.: Inventories of $\mathrm{N}_{2} \mathrm{O}$ and $\mathrm{NO}$ emissions from European forest soils, Biogeosciences, 2, 353-375, doi:10.5194/bg2-353-2005, 2005.

Kiese, R., Heinzeller, C., Werner, C., Wochele, S., Grote, R., and Butterbach-Bahl, K.: Quantification of nitrate leaching from German forest ecosystems by use of a process oriented biogeochemical model, Environ. Pollut., 159, 3204-3214, doi:10.1016/j.envpol.2011.05.004, 2011.

Körner, C.: Carbon limitation in trees, J. Ecol., 91, 4-17, 2003.

LeBauer, D. S. and Treseder, K. K.: Nitrogen limitation of net primary productivity in terrestrial ecosystems is globally distributed, Ecology, 89, 371-379, doi:10.1890/06-2057.1, 2008.

Leip, A., Marchi, G., Koeble, R., Kempen, M., Britz, W., and Li, C.: Linking an economic model for European agriculture with a mechanistic model to estimate nitrogen and carbon losses from arable soils in Europe, Biogeosciences, 5, 73-94, doi:10.5194/bg-5-73-2008, 2008.

Leip, A., Busto, M., and Winiwarter, W.: Developing spatially stratified $\mathrm{N}_{2} \mathrm{O}$ emission factors for Europe, Environ. Pollut., 159, 3223-3232, doi:10.1016/j.envpol.2010.11.024, 2011.

Li, C., Frolking, S., and Frolking, T. A.: A model of nitrous-oxide evolution from soil driven by rainfall events. 1. Model structure and sensitivity, J. Geophys. Res., 97, 9759-9776, 1992.

Li, C., Aber, J., Stange, F., Butterbach-Bahl, K., and Papen, H.: A process-oriented model of $\mathrm{N}_{2} \mathrm{O}$ and $\mathrm{NO}$ emissions from forest soils: 1. Model development, J. Geophys. Res.-Atmos., 105, 4369-4384, 2000.

Liski, J., Nissinen, A., Erhard, M., and Taskinen, O.: Climatic effects on litter decomposition from arctic tundra to tropical rainforest, Glob. Change Biol., 9, 575-584, doi:10.1046/j.13652486.2003.00605.x, 2003. 
Liski, J., Palosuo, T., Peltoniemi, M., and Sievänen, R.: Carbon and decomposition model Yasso for forest soils, Ecol. Modell., 189, 168-182, doi:10.1016/j.ecolmodel.2005.03.005, 2005.

Luyssaert, S., Ciais, P., Piao, S. L., Schulze, E., Jung, M., Zaehle, S., Schelhaas, M. J., Reichstein, M., Churkina, G., Papale, D., Abril, G., Beer, C., Grace, J., Loustau, D., Matteucci, G., Magnani, F., Nabuurs, G. J., Verbeeck, H., Sulkava, M., Van der Werf, G. R., Janssens, I. A., and Team, m. o. t. C. S.: The European carbon balance. Part 3: forests, Glob. Change Biol., 16, 1429-1450, doi:10.1111/j.1365-2486.2009.02056.x, 2010.

Magill, A. H., Aber, J. D., Currie, W. S., Nadelhoffer, K. J., Martin, M. E., McDowell, W. H., Melillo, J. M., and Steudler, P.: Ecosystem response to 15 years of chronic nitrogen additions at the Harvard Forest LTER, Massachusetts, USA, Forest Ecol. Manag., 196, 7-28, 2004.

Magnani, F., Mencuccini, M., Borghetti, M., Berbigier, P., Berninger, F., Delzon, S., Grelle, A., Hari, P., Jarvis, P. G., Kolari, P., Kowalski, A. S., Lankreijer, H., Law, B. E., Lindroth, A., Loustau, D., Manca, G., Moncrieff, J. B., Rayment, M., Tedeschi, V., Valentini, R., and Grace, J.: The human footprint in the carbon cycle of temperate and boreal forests, Nature, 447, 849-851, doi:10.1038/nature05847, 2007.

Millennium Ecosystem Assessment: Ecosystems and Human Well-being Synthesis, Tech. Rep., Island Press, Washington, DC, available at: www.millenniumassessment.org/documents/ document.356.aspx.pdf, 2005.

Myneni, R. B., Keeling, C. D., Tucker, C. J., Asrar, G., and Nemani, R. R.: Increased plant growth in the northern high latitudes from 1981 to 1991, Nature, 386, 698-702, 1997.

Nabuurs, G.-J., Schelhaas, M.-J., Mohren, G. M. J., and Field, C. B.: Temporal evolution of the European forest sector carbon sink from 1950 to 1999 , Glob. Change Biol., 9, 152-160, doi:10.1046/j.1365-2486.2003.00570.x, 2003.

Nakícenovíc, N., Alcamo, J., Davis, G., De Vries, B., Fenhann, J., Gaffin, S., Gregory, K., Grübler, A., Jung, T. Y., Kram, T., Emilio la Rovere, E., Michaelis, L., Mori, S., Morita, T., Pepper, W., Pitcher, H., Price, L., Riahi, K., Roehrl, A., Rogner, H.H., Sankovski, A., Schlesinger, M. E., Shukla, P. R., Smith, S., Swart, R. J., van Rooyen, S., Victor, N., and Dadi, Z.: Special Report on Emission Scenarios: Intergovernmental Panel on Climate Change, Cambridge University Press, Cambridge, 2001.

Parton, W. J. and Rasmussen, P. E.: Long-term effects of crop management in wheat-fallow: II. CENTURY model simulations, Soil Sci. Soc. Am. J., 58, 530-536, 1994.

Parton, W. J., Holland, E. A., Del Grosso, S. J., Hartman, M. D., Martin, R. E., Mosier, A. R., Ojima, D. S., and Schimel, D. S.: Generalized model for NO $\mathrm{x}$ and $\mathrm{N} 2 \mathrm{O}$ emissions from soils, J. Geophys. Res., 106, 17403-17417, 2001.

Pilegaard, K., Skiba, U., Ambus, P., Beier, C., Brüggemann, N., Butterbach-Bahl, K., Dick, J., Dorsey, J., Duyzer, J., Gallagher, M., Gasche, R., Horvath, L., Kitzler, B., Leip, A., Pihlatie, M. K., Rosenkranz, P., Seufert, G., Vesala, T., Westrate, H., and Zechmeister-Boltenstern, S.: Factors controlling regional differences in forest soil emission of nitrogen oxides ( $\mathrm{NO}$ and $\mathrm{N}_{2} \mathrm{O}$ ), Biogeosciences, 3, 651-661, doi:10.5194/bg-3-651-2006, 2006.

Poorter, H. and Nagel, O.: The role of biomass allocation in the growth response of plants to different levels of light, $\mathrm{CO}_{2}$, nutrients and water: a quantitative review, Funct. Plant Biol., 27, 1191-1191, 2000.
Rawls, W. J., Brakensiek, D. L., and Saxton, K. E.: Estimation of soil water properties, Trans. Asae, 25, 1316-1320, 1982.

Rebetez, M. and Dobbertin, M.: Climate change may already threaten Scots pine stands in the Swiss Alps, Theor. Appl. Climatol., 79, 1-9, 2004.

Robertson, G. P.: Standard soil methods for long-term ecological research, vol. 2, Oxford University Press, USA, 1999.

Schelhaas, M., J. van Brusselen, J., Pussinen, A., Pesonen, E., Schuck, A., Nabuurs, G., and Sasse, V.: Outlook for the Development of European Forest Resources. A study prepared for the European Forest Sector Outlook Study (EFSOS), Tech. Rep., Geneva Timber and Forest Discussion Paper, ECE/TIM/DP/41, UN-ECE, Geneva, 2006a.

Schelhaas, M. J., Varis, S., Schuck, A., and Nabuurs, G. J.: EFISCEN Inventory Database, European Forest Institute, Joensuu, Finland, available at: http://www.efi.int/portal/virtual_library/ databases/efiscen/, 2006b.

Schelhaas, M., Eggers, J., Lindner, M., Nabuurs, G., Pussinen, A., Päivinen, R., Schuck, A., Verkerk, P., van der Werf, D., and Zudin, S.: Model documentation for the European Forest Information Scenario Model (EFISCEN 3.1.3), Alterra, Wageningen, available at: http://www.efi.int/portal/virtual_library/ databases/efiscen/, 2007.

Simpson, D., Fagerli, H., Jonson, J., Tsyro, S., Wind, P., and Tuovinen, J.-P.: Transboundary Acidification, Eutrophication and Ground Level Ozone in Europe PART I. Unified EMEP Model Description, EMEP Status Report 2003, Tech. rep., Norwegian Meteorological Institute, Oslo, Norway, 2003.

Solberg, S., Dobbertin, M., Reinds, G. J., Lange, H., Andreassen, K., Fernandez, P. G., Hildingsson, A., and De Vries, W.: Analyses of the impact of changes in atmospheric deposition and climate on forest growth in European monitoring plots: A stand growth approach, Forest Ecol. Manag., 258, 1735-1750, 2009.

Solomon, S., Qin, D., Manning, M., Chen, Z., Marquis, M., Averyt, K. B., Tignor, M., and Miller, H. L.: Contribution of working group I to the fourth assessment report of the intergovernmental panel on climate change, Cambridge, UK, Cambridge University Press, 452-454, p. 457, 2007.

Spiecker, H.: Overview of recent growth trends in European forests, Water, Air, Soil Pollut., 116, 33-46, 1999.

Sutton, M. A., Simpson, D., Levy, P. E., Smith, R. I., Reis, S., Van Oijen, M., and De Vries, W.: Uncertainties in the relationship between atmospheric nitrogen deposition and forest carbon sequestration, Glob. Change Biol., 14, 2057-2063, 2008.

Tarrasón, L., Fagerli, H., Jonson, J., Simpson, D., Benedictow, A., Klein, H., Vestreng, V., Aas, W., and Hjellbrekke, A.-G.: Transboundary acidification, eutrophication and ground level ozone in Europe in 2005, EMEP Report 1/2007, Tech. Rep., Norwegian Meteorological Institute, Oslo, Norway, 2007.

Turner, D. P., Koerper, G. J., Harmon, M. E., and Lee, J. J.: A carbon budget for forests of the conterminous United States, Ecol. Appl., 5, 421-436, 1995.

van Genuchten, M. T.: A closed-form equation for predicting the hydraulic conductivity of unsaturated soils, Soil Sci. Soc. Am. J., 44, 892-898, 1980.

Van Oijen, M. and Thomson, A.: Toward Bayesian uncertainty quantification for forestry models used in the United Kingdom Greenhouse Gas Inventory for land use, land use change, and forestry, Clim. Change, 103, 55-67, doi:10.1007/s10584-010- 
9917-3, 2010.

Van Oijen, M., Cannell, M. G. R., and Levy, P. E.: Modelling biogeochemical cycles in forests: state of the art and perspectives, Towards the sustainable use of European forests-Forest ecosystem and landscape research: scientific challenges and opportunities, edited by: Andersson, F., Birot, Y., and Päivinen, R., European Forest Institute, Joensuu, Finnland, 157-169, 2004.

Van Oijen, M., Rougier, J., and Smith, R.: Bayesian calibration of process-based forest models: bridging the gap between models and data, Tree Physiol., 25, 915-927, doi:10.1093/treephys/25.7.915, 2005.

Van Oijen, M., Cameron, D. R., Butterbach-Bahl, K., Farahbakhshazad, N., Jansson, P.-E., Kiese, R., Rahn, K.-H., Werner, C., and Yeluripati, J. B.: A Bayesian framework for model calibration, comparison and analysis: Application to four models for the biogeochemistry of a Norway spruce forest, Agr. Forest Meteorol., 151, 1609-1621, doi:10.1016/j.agrformet.2011.06.017, 2011.
Vitousek, P. M. and Howarth, R. W.: Nitrogen limitation on land and in the sea: how can it occur?, Biogeochemistry, 13, 87-115, 1991.

Vitousek, P.: Nutrient Cycling and Nutrient Use Efficiency, The American Naturalist, 119, 553-572, 1982.

Wamelink, G. W. W., Wieggers, H. J. J., Reinds, G. J., Kros, J., Mol-Dijkstra, J. P., Van Oijen, M., and De Vries, W.: Modelling impacts of changes in carbon dioxide concentration, climate and nitrogen deposition on carbon sequestration by European forests and forest soils, Forest Ecol. Manag., 258, 1794-1805, 2009.

Yeluripati, J. B., Van Oijen, M., Wattenbach, M., Neftel, A., Ammann, A., Parton, W. J., and Smith, P.: Bayesian calibration as a tool for initialising the carbon pools of dynamic soil models, Soil Biol. Biochem., 41, 2579-2583, 2009.

Zweifel, R., Steppe, K., and Sterck, F. J.: Stomatal regulation by microclimate and tree water relations: interpreting ecophysiological field data with a hydraulic plant model, J. Experiment. Botany, 58, 2113-2131, 2007. 